\title{
Combined genome and transcriptome sequencing to investigate the plant cell wall degrading enzyme system in the thermophilic fungus Malbranchea cinnamomea
}

\author{
Silvia Hüttner ${ }^{1,2^{*}} \mathbb{1}$, Thanh Thuy Nguyen ${ }^{3}$, Zoraide Granchi ${ }^{4}$, Thomas Chin-A-Woeng ${ }^{4}$, Dag Ahrén ${ }^{5}$,
} Johan Larsbrink ${ }^{1,2}$, Vu Nguyen Thanh ${ }^{3}$ and Lisbeth Olsson ${ }^{1,2}$

\begin{abstract}
Background: Genome and transcriptome sequencing has greatly facilitated the understanding of biomass-degrading mechanisms in a number of fungal species. The information obtained enables the investigation and discovery of genes encoding proteins involved in plant cell wall degradation, which are crucial for saccharification of lignocellulosic biomass in second-generation biorefinery applications. The thermophilic fungus Malbranchea cinnamomea is an efficient producer of many industrially relevant enzymes and a detailed analysis of its genomic content will considerably enhance our understanding of its lignocellulolytic system and promote the discovery of novel proteins.

Results: The 25-million-base-pair genome of $M$. cinnamomea FCH 10.5 was sequenced with $225 \times$ coverage. A total of 9437 protein-coding genes were predicted and annotated, among which 301 carbohydrate-active enzyme (CAZyme) domains were found. The putative CAZymes of M. cinnamomea cover cellulases, hemicellulases, chitinases and pectinases, equipping the fungus with the ability to grow on a wide variety of biomass types. Upregulation of 438 and 150 genes during growth on wheat bran and xylan, respectively, in comparison to growth on glucose was revealed. Among the most highly upregulated CAZymes on xylan were glycoside hydrolase family GH10 and GH11 xylanases, as well as a putative glucuronoyl esterase and a putative lytic polysaccharide monooxygenase (LPMO). AA9-domain-containing proteins were also found to be upregulated on wheat bran, as well as a putative cutinase and a protein harbouring a CBM9 domain. Several genes encoding secreted proteins of unknown function were also more abundant on wheat bran and xylan than on glucose.
\end{abstract}

Conclusions: The comprehensive combined genome and transcriptome analysis of $\mathrm{M}$. cinnamomea provides a detailed insight into its response to growth on different types of biomass. In addition, the study facilitates the further exploration and exploitation of the repertoire of industrially relevant lignocellulolytic enzymes of this fungus.

Keywords: Plant biomass, Carbohydrate-active enzymes, Cellulase, Wheat bran, Xylan, Malbranchea pulchella

\section{Background}

Conventional resources, such as oil, gas and coal, used in the production of fuels and chemicals are becoming limited and are the cause of many environmental problems.

\footnotetext{
*Correspondence: huttner@chalmers.se

${ }^{1}$ Department of Biology and Biological Engineering, Division of Industrial Biotechnology, Chalmers University of Technology, 41296 Gothenburg, Sweden

Full list of author information is available at the end of the article
}

The alternative use of renewable and abundant (ligno)cellulosic materials, i.e. plant cell walls, as feedstocks in second-generation biorefineries has consequently been the subject of intense research and innovation during recent decades [1-3]. Microbial cells and their enzymes are here utilised to convert low-value biomass into valuable products such as biofuels and biochemicals. Still, efficient saccharification of the lignocellulosic material remains challenging. Lignocellulose consists of a heterogeneous 
matrix comprising crystalline cellulose microfibrils enmeshed in a matrix of various types of hemicelluloses and pectins, and in addition contains significant amounts of the polyaromatic structure lignin [4]. A large number of enzymatic activities are required to fully deconstruct plant biomass, most of which are catalogued in the carbohydrate-active enzymes database (CAZy) [5-7]. These carbohydrate-active enzymes (CAZymes) are involved in the assembly and breakdown of complex carbohydrates and glycoconjugates, and have been classified into glycoside hydrolases (GHs), glycosyltransferases (GTs), polysaccharide lyases (PLs), carbohydrate esterases (CEs), enzymes with auxiliary activities (AAs) and carbohydrate-binding modules (CBMs).

Fungi are main degraders of plant biomass in nature and fungal CAZymes from both Ascomycetes and Basidiomycetes are widely used in industrial processes [8-10]. Most enzymes used today in biomass conversion are mesophilic, but higher process temperatures could enable faster reaction rates, lower viscosity, better cell wall disintegration and enzyme penetration into the raw material, increased mass transfer and reduced risk of contamination [11-14]. Therefore, thermophilic organisms, with growth optima between 45 and $80{ }^{\circ} \mathrm{C}$ [15], are promising sources of thermostable enzymes and have hitherto not been as extensively explored as their mesophilic counterparts [16].

The thermophilic fungus Malbranchea cinnamomea belongs to the order of Onygenales [17], can grow at temperatures over $50{ }^{\circ} \mathrm{C}$ and is able to utilise many different types of plant biomass, including rice straw, sorghum, corn cob, wheat bran, coconut meal and Parthenium hysterophorus (carrot grass), as well as crystalline cellulose [16, 18-25]. When grown on carrot grass and rice straw, $M$. cinnamomea has been found to be the most efficient source of GHs among nine thermophilic fungi tested [26]. Characterised enzymes from $M$. cinnamomea include a $\beta$-mannanase [18], an alkaline $\beta$-1,3-1,4-glucanase (lichenase) [19], an $\alpha$-amylase [20], an $\alpha$-glucosidase [21], xylanases [22-24] and a cutinase [25], all of which have been reported to have temperature optima between 45 and $80^{\circ} \mathrm{C}$ (Additional file 1). A proteomics analysis of $M$. cinnamomea CM-10T, using the sequence of $M$. cinnamomea strain CBS 343.55 [27], revealed a large array of enzymes from major GH families involved in efficient biomass degradation [26], but to the best of our knowledge no detailed genome analyses have been published to date. We here expand the existing knowledge of $M$. cinnamomea with a combined genome sequencing and transcriptomic analysis of strain $\mathrm{FCH}$ 10.5 to provide a comprehensive view of its lignocellulolytic capabilities. We identified genes differentially expressed during growth on beechwood xylan and wheat bran, which indicate differences in the strategy of the fungus to deconstruct hardwood and cereal hemicelluloses. The data presented here will form a basis for systematic exploration of the full potential of M. cinnamomea as a source of thermostable enzymes.

\section{Methods}

\section{Fungal isolation, identification and cultivation}

The fungus used in the present study was isolated from compost at the Cau Dien municipal waste treatment factory in Hanoi, Vietnam [geographical location $21^{\circ} 01^{\prime} 01.7^{\prime \prime} \mathrm{N}, 105^{\circ} 45^{\prime} 09.2^{\prime \prime} \mathrm{E}, 11 \mathrm{~m}$ (longitude, latitude, altitude)], and was grown on potato dextrose agar (PDA) at $50{ }^{\circ} \mathrm{C}$. For DNA extraction and species identification, one loopful of mycelium was transferred to a microcentrifuge tube containing $1 \mathrm{~mL}$ 2X SSC ( $15 \mathrm{mM}$ sodium citrate, $150 \mathrm{mM} \mathrm{NaCl}, \mathrm{pH} \mathrm{7.0)}$ and heated to $99^{\circ} \mathrm{C}$ for $10 \mathrm{~min}$. Cells were collected by centrifugation $(10,000 \mathrm{~g}$, $1 \mathrm{~min}$ ), the supernatant was discarded, and $100 \mu \mathrm{L}$ of glass beads $(0.2-0.5 \mathrm{~mm}$ in diameter; Roth, Germany), $100 \mu \mathrm{L}$ phenol-chloroform (25:24:1, saturated with $10 \mathrm{mM}$ TrisHCl, $\mathrm{pH}$ 8.0) and $150 \mu \mathrm{L}$ water were added to the cell pellet. The cells were disrupted using a MiniBeadbeater-8 (Biospec, USA) for $45 \mathrm{~s}$, then centrifuged $(14,000 \mathrm{~g}, 10 \mathrm{~min})$, and the upper layer of liquid was transferred to a new tube. The DNA solutions were purified using a Silica Bead DNA Gel Extraction kit (Thermo Scientific), according to the manufacturer's instructions. The resulting DNA was used to amplify the internal transcribed spacer (ITS) regions using the universal primers ITS1 (forward; 5' TCCGTAGGTGAACCTGCGG $3^{\prime}$ ) and ITS4 (reverse; $5^{\prime}$ TCCTCCGCTTATTGATATGC $3^{\prime}$ ) [28]. Amplicons were sequenced, compared to available databases using BLAST and the fungus was identified as $M$. cinnamomea. The ITS sequence of FCH 10.5 was compared with ITS sequences of other M. cinnamomea strains in Genbank by multiple sequence alignment (see Additional file 2). The strain FCH 10.5 has been deposited at the CBS-KNAW fungal culture collection [29] and the ITS sequence has been deposited at NCBI Genbank under the Accession Number MF838862.1.

\section{Growth on plates with different carbon sources}

M. cinnamomea, Myceliophthora thermophila, Aspergillus oryzae, Phanerochaete chrysosporium and Schizophyllum commune (all from our own culture collection, except A. oryzae JCM 2239 from the Japan Collection of Microorganisms) were grown on plates containing a basal medium $\left(4 \mathrm{~g} \mathrm{~L}^{-1} \mathrm{KH}_{2} \mathrm{PO}_{4}, 13.6 \mathrm{~g} \mathrm{~L}^{-1}\left(\mathrm{NH}_{4}\right)_{2} \mathrm{SO}_{4}\right.$, $0.8 \mathrm{~g} \mathrm{~L}^{-1} \mathrm{CaCl}_{2} \cdot 2 \mathrm{H}_{2} \mathrm{O}, 0.6 \mathrm{~g} \mathrm{~L}^{-1} \mathrm{MgSO}_{4} \cdot 7 \mathrm{H}_{2} \mathrm{O}, 6 \mathrm{~g} \mathrm{~L}^{-1}$ Bacto peptone, $10 \mathrm{mg} \mathrm{L}^{-1} \mathrm{FeSO}_{4} \cdot 7 \mathrm{H}_{2} \mathrm{O}, 3.2 \mathrm{mg} \mathrm{L} \mathrm{L}^{-1}$ $\mathrm{MnSO}_{4} \cdot \mathrm{H}_{2} \mathrm{O}, 2.8 \mathrm{mg} \mathrm{L} \mathrm{L}^{-1} \mathrm{ZnSO}_{4} \cdot 7 \mathrm{H}_{2} \mathrm{O}, 4 \mathrm{mg} \mathrm{L} \mathrm{L}^{-1}$ $\mathrm{CoCl}_{2} \cdot 6 \mathrm{H}_{2} \mathrm{O}, 200 \mathrm{~mL} \mathrm{~L}^{-1}$ Tween 80 ), and $15 \mathrm{~g} \mathrm{~L}^{-1}$ agar. 
The $\mathrm{pH}$ was adjusted to 5.8 and carbon sources were added before autoclaving. As carbon source, 1\% of Avicel, beechwood xylan, starch, guar gum, gum arabic, carboxymethyl cellulose (CMC), citrus pectin, chitosan, locust bean gum or inulin from Dahlia tubers, or $0.5 \%$ of cellobiose, D-galactose, D-glucose, D-mannose or D-xylose, respectively, was added. All chemicals were obtained from Sigma-Aldrich, except D-glucose from Merck and D-xylose from Fluka. Plates were inoculated with spores and grown at $30^{\circ} \mathrm{C}$ or $50^{\circ} \mathrm{C}$ for 7 days.

\section{Enzyme activity assays}

Liquid cultures of $M$. cinnamomea FCH 10.5 were grown in $125 \mathrm{~mL}$ liquid medium in baffled Erlenmeyer flasks $(500 \mathrm{~mL})$, containing the basal medium supplemented with $1 \%$ wheat bran or $1 \%$ beechwood xylan. The liquid cultures were inoculated with a spore suspension prepared from a fresh PDA plate. Cultures were grown at $50{ }^{\circ} \mathrm{C}$ for 9 days with shaking at $250 \mathrm{rpm}$, and samples taken every $24 \mathrm{~h}$. For determination of xylanase or endoglucanase activity, $0.1 \mathrm{~mL}$ of crude culture filtrate was mixed with $0.2 \mathrm{~mL}$ of substrate (1\% xylan or $1 \% \mathrm{CMC}$ ). After incubation at $50{ }^{\circ} \mathrm{C}$ for $20 \mathrm{~min}, 0.6 \mathrm{~mL}$ DNS reagent, consisting of $1 \%(\mathrm{w} / \mathrm{v})$ dinitrosalicylic acid (DNS), $0.2 \%(\mathrm{w} / \mathrm{v})$ phenol and $1 \%(\mathrm{w} / \mathrm{v}) \mathrm{NaOH}$, were added and kept at $95{ }^{\circ} \mathrm{C}$ for $5 \mathrm{~min}$. The sample was cooled down, $0.4 \mathrm{~mL}$ were mixed with $1.8 \mathrm{~mL}$ water and the absorbance was measured at $540 \mathrm{~nm}$. Standard curves were prepared with xylose and glucose.

\section{DNA and RNA extraction}

Cultivation of fungal mycelium for genome sequencing was carried out in $125 \mathrm{~mL}$ liquid medium in baffled Erlenmeyer flasks $(500 \mathrm{~mL})$ at $50{ }^{\circ} \mathrm{C}$ for $48 \mathrm{~h}$ on a shaking incubator at $250 \mathrm{rpm}$ in basal medium with glucose as the carbon source $\left(20 \mathrm{~g} \mathrm{~L}^{-1}\right)$. The liquid culture was inoculated with a spore suspension prepared from a fresh PDA plate. After 2 days of cultivation, mycelium was harvested by filtering through Miracloth (Merck Millipore) in a Büchner filter. After pressing between paper towels, the mycelium was snap frozen in liquid nitrogen and stored at $-80{ }^{\circ} \mathrm{C}$ until DNA extraction. Cells were broken using a tissue lyser with tungsten steel balls, precooled in liquid nitrogen, for $30 \mathrm{~s}$ at full speed. Immediately, $20 \mathrm{~mL}$ CTAB buffer (2\% CTAB, $100 \mathrm{mM}$ Tris $\mathrm{HCl}$, pH 8.0, $20 \mathrm{mM}$ EDTA, $1.4 \mathrm{M} \mathrm{NaCl}$ ) were added to $\sim 5 \mathrm{~mL}$ mycelium powder. After incubation at $57^{\circ} \mathrm{C}$ for $1 \mathrm{~h}$, cell debris was spun down $\left(10,000 \mathrm{~g}, 10 \mathrm{~min}, 4^{\circ} \mathrm{C}\right)$ and DNA was purified from the supernatant by phenol-chloroform extraction and isopropanol precipitation [30]. The final DNA pellet was resuspended in $1 \mathrm{~mL}$ TE buffer $(10 \mathrm{mM}$ TrisHCl, pH 8.0, $1 \mathrm{mM}$ EDTA). After incubation at $60{ }^{\circ} \mathrm{C}$ for $2 \mathrm{~h}$ with RNAse A (200 mg/mL), DNA was again extracted by phenol-chloroform extraction, precipitated with isopropanol and purified in a further step with the DNeasy Plant Mini Kit (Qiagen), according to the manufacturer's instructions. Quality of the purified DNA was verified by agarose gel electrophoresis, Nanodrop (Thermo Scientific) and Qubit (Life Technologies) before genome sequencing.

For RNA extraction, $2 \times 200 \mathrm{~mL}$ of pre-culture were cultivated for 2 days (in 1000-mL baffled Erlenmeyer flasks) in glucose-containing liquid medium, as described above, after which the mycelium was filtered and extensively washed with medium lacking a carbon source. A total of $15 \mathrm{~g}$ of mycelium was then divided equally between six 250-mL baffled Erlenmeyer flasks containing $50 \mathrm{~mL}$ basal liquid medium supplemented with either $10 \mathrm{~g} \mathrm{~L}^{-1}$ glucose, wheat bran or beechwood xylan as the sole carbon sources. Two independent duplicate experiments were performed for each substrate. After 4 and $48 \mathrm{~h}$ of incubation at $50{ }^{\circ} \mathrm{C}$ on a shaking incubator, total RNA was extracted using TRIzol (Invitrogen) and chloroform, and further purified with the RNeasy Plant RNA Kit with on-column DNAse digestion. The quality of the purified RNA was verified by agarose gel electrophoresis, Nanodrop (Thermo Scientific) and Qubit (Life Technologies). Subsequent RNA sequencing was performed with a 1:1 mixture of RNA samples isolated at 4 and $48 \mathrm{~h}$, to increase the chances of detecting both early- and lateresponse genes in the differential expression analysis. However, the transcriptional response of genes induced only at the early or later time point may be diluted.

\section{Genome sequencing and assembly}

The NEBNext Ultra DNA Library Prep kit for Illumina (New England Biolabs) was used to process the samples according to the manufacturer's protocol. Fragmentation of DNA was carried out using a Covaris ultrasonicator (Thermo Scientific). The quality and yield after sample preparation were measured using Bioanalyzer (Agilent Technologies). Clustering and DNA sequencing were performed using the Illumina cBot and HiSeq 2500 systems with a DNA concentration of $8.0 \mathrm{pM}$, using 250-bp paired-end reads. Procedures were carried out by GenomeScan B.V., Leiden. Image analysis, base calling and quality check were performed with the Illumina data analysis pipelines RTA v1.18.64 and Bcl2fastq v1.8.4. For adapter trimming, presumed adapter sequences were removed from the read when the bases matched a sequence in the TruSeq adapter sequence set with 2 or fewer mismatches and an alignment score of at least 12 . Raw data were filtered and clipped based on base quality scores; bases with Phred quality scores below Q22 were removed and reads containing these bases were split and removed when shorter than $36 \mathrm{bp}$. A short-read genome 
assembler based on De Bruijn graphs, Abyss v1.3.7 [31, $32]$, with a k-mer length of 64 was used for assembly. Scaffolds shorter than 500 bp were removed. The M. cinnamomea $\mathrm{FCH} 10.5$ whole genome assembly has been submitted to the European Nucleotide Archive and deposited at DDBJ/EMBL/GenBank under the assembly Accession Number FQSS02000000.

\section{Transcriptome analysis}

The NEBNext Ultra Directional RNA Library Prep Kit for Illumina (New England Biolabs) was used to process the samples according to the manufacturer's instructions. Briefly, mRNA was isolated from total RNA using oligodT magnetic beads and used to synthesise cDNA. The CDNA was ligated with sequencing adapters and PCR amplified. The quality and yield after sample preparation were determined with the Fragment Analyzer (Advanced Analytical). The size of the resulting products was consistent with the expected size distribution (a broad peak between 300 and $500 \mathrm{bp}$ ). Standard Illumina primers for Illumina cBot and HiSeq 2500, and the HiSeq control software HCS v2.2.58 were used according to the manufacturer's protocols for clustering and DNA sequencing with a concentration of $16.0 \mathrm{pM}$. The Illumina data analysis pipelines RTA v1.18.64 and Bcl2fastq v2.17 were used for image analysis, base calling and quality check. Sequencing was performed on an Illumina HiSeq 2500 sequencer. The assembled genome from the DNA sequencing was used as a reference to map the reads using the packages Tophat (v2.0.14. Linux_x86_64) and Bowtie (v2-2.1.0) with a default mismatch rate of $2 \%$. The frequency with which a read was mapped on a transcript was determined based on the mapped locations from the alignment. To normalise for transcript length, fpkm (fragments per kilobase of transcript per million mapped reads) were calculated. For differential expression analysis, the read counts were loaded into the DESeq package v 1.10.1 [31]. Genes were considered differentially expressed if they showed a log2 fold change $\geq 1$ and the adjusted $p$ value was $<0.05$. The reproducibility of biological replicates is shown in Additional file 2.

\section{Gene prediction and annotation}

Gene prediction was performed ab initio using the HMM-based algorithm Glimmer v. 3.02 [33], which was trained using the genome of Uncinocarpus reesii (downloaded from JGI, [34]). Additionally, the software tool CodingQuarry [35] was used for an evidence-based method of gene finding, where exon-intron boundaries were determined using the mapped mRNA-seq reads. For functional gene annotation, coding DNA sequences (CDS) were translated into amino acid sequences and a BLASTp search (version 2.2.28+) [36] was performed on the UniprotKB/Swiss-prot database with default parameters ( $E$ value cut-off of 1, similarity cut-off of 30\%). Classification into gene ontology (GO) categories and InterProScan were performed with Blast2GO software [37]. GO enrichment tests were performed with the $R$ package Piano [38]. Secretory proteins were predicted using the SignalP 4.1 Server [39] or the WoLF PSORT algorithm [40]. Genes containing CAZy domains were identified using dbCAN release 5.0 [41] which searches CAZy family-specific HMMs with HMMER3, and NCBI's conserved domain database CDD [42].

\section{Results}

Strain identification and growth on different carbohydrates Strain FCH 10.5, isolated from compost at a municipal waste treatment plant in Hanoi and identified as M. cinnamomea by ITS sequencing, grew well on PDA at $50{ }^{\circ} \mathrm{C}$ and formed yellow, powdery colonies of irregular shape and produced curved, fertile hyphae and arthroconidia (Fig. 1a, b), as described previously [43]. A comparison of ITS sequences to other $M$. cinnamomea strains in the NCBI Genbank database revealed a very high sequence identity of strain FCH 10.5 to CM-10T, isolated from composting soil near Punjab, India, which had been the subject of an earlier proteomics analysis [26] (Additional file 3).

Previous studies have shown that $M$. cinnamomea has high cellulolytic and hemicellulolytic activities when cultivated on wheat bran, rice straw, sorghum straw or cellulose [16, 27, 44]. We also detected xylanase and endoglucanase activities in liquid cultures of $\mathrm{FCH} 10.5$ grown on wheat bran or beechwood xylan (Additional file 4). During growth on xylan, higher xylanase activities were observed than during growth on wheat bran, while cultures on wheat bran showed a higher endoglucanase activity. The peak of enzymatic activity was reached at between 6 and 8 days of cultivation.

The growth of M. cinnamomea FCH 10.5 on various, mono-, di-, and polysaccharides was evaluated in comparison to a selection of both thermophilic and mesophilic strains (Fig. 1c and Additional file 5). The preferred substrates of M. cinnamomea FCH 10.5 among the tested ones were beechwood xylan, cellobiose and starch. Good growth could also be observed on inulin and locust bean gum (galactomannan with galactose residues on every fourth mannose), while only poor growth was observed on guar gum (galactomannan with galactose residues on every second mannose) and cellulose (Avicel, CMC). No growth was detected on citrus pectin as the sole carbon source.

\section{Genome characteristics}

The whole genome sequence of $M$. cinnamomea $\mathrm{FCH}$ 10.5 was determined by sequencing on the Illumina HiSeq 2500 platform. Libraries of 300- to 500- and 


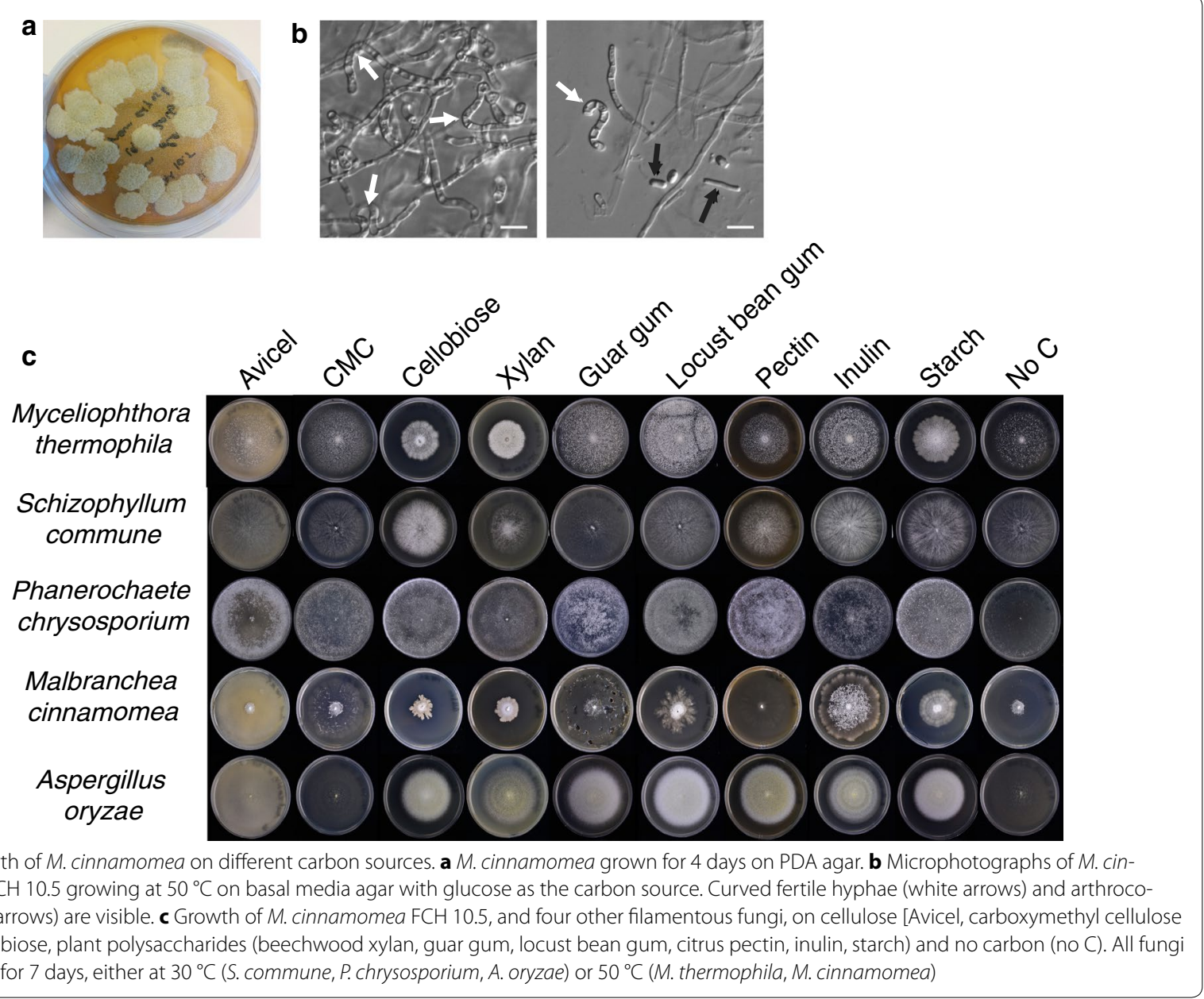

500 - to 800 -bp fragments were sequenced to produce 250-bp paired-end reads. This produced raw yields of 3.5 and $2.6 \mathrm{~Gb}$, respectively. The quality was determined as the percentage of bases with a $Q$ score $\geq 30$, and was greater than $88 \%$ in both cases. The final genome size of the assembly was $24.96 \mathrm{Mb}$ comprising 797 scaffolds. The output of two gene prediction algorithms (Glimmer and CodingQuarry) was combined into a single gene model and yielded 9437 protein-coding genes with an average length of 388 amino acids. Both the size of the assembled $M$. cinnamomea sequence and the number of predicted protein-coding genes fell into the range of other sequenced fungal genomes [45]. Species in the order Onygenales have genome sizes of about $25 \mathrm{Mb}$ and contain on average around 8700 protein-coding genes [46]. The GC content of the M. cinnamomea genome was determined to be $53.4 \%$ for coding regions and $49.8 \%$ for the overall genome. To better describe integrity of the genome assembly, Benchmarking Universal SingleCopy Orthologs (BUSCO) analysis was performed, a method for quantitative assessment of genome assembly and annotation completeness [47]. The presence of the BUSCO set of 1438 well-conserved, fungal single-copy genes was determined in the genome of $\mathrm{FCH}$ 10.5. Of those, 1357 were found to be complete (C: $94 \%$ ), indicating an assembly of excellent integrity. Additional file 6 summarises the $M$. cinnamomea $\mathrm{FCH} 10.5$ genome properties.

Average, shortest and longest sizes of the 9437 predicted proteins were 338, 49 and 8085 amino acids, respectively (Fig. 2a), with the majority of proteins being between 143 (25th percentile) and 514 (75th percentile) amino acids long. With the selected parameters, $25 \%$ of the predicted proteins could not be annotated by BLASTp. Among the proteins with BLASTp hits, $0.45 \%$ showed a similarity of over $90 \%$ to proteins in the UniprotKB/Swiss-prot database, $6.65 \%$ a similarity of between 70 and 89 , and $39.01 \%$ a similarity of $50-69 \%$ (Fig. 2b, Additional file 6). Over half of the protein sequences of $M$. cinnamomea could be annotated with an $E$ value of below $10^{-9}$ (Fig. 2c), which indicates high confidence in the annotation results. A GO classification 


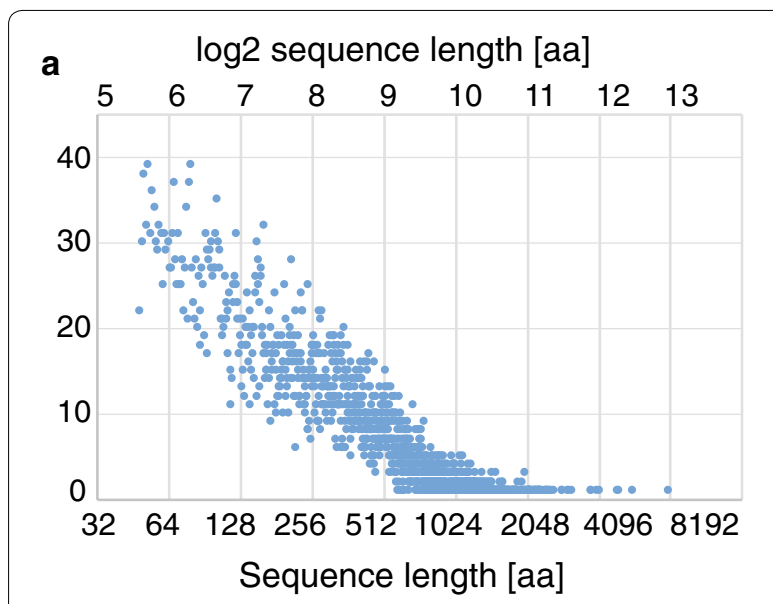

b

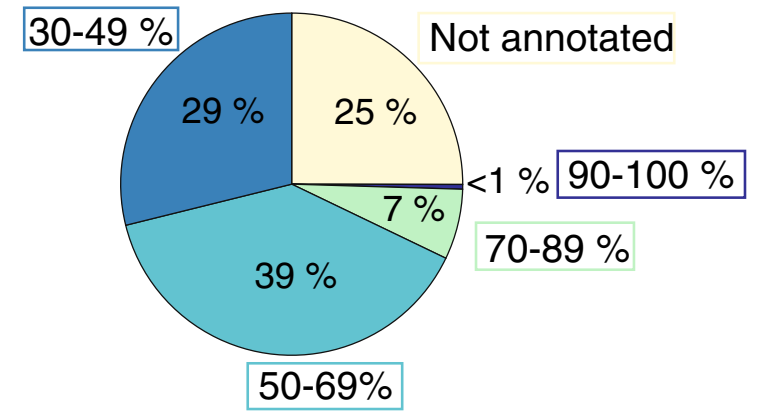

C

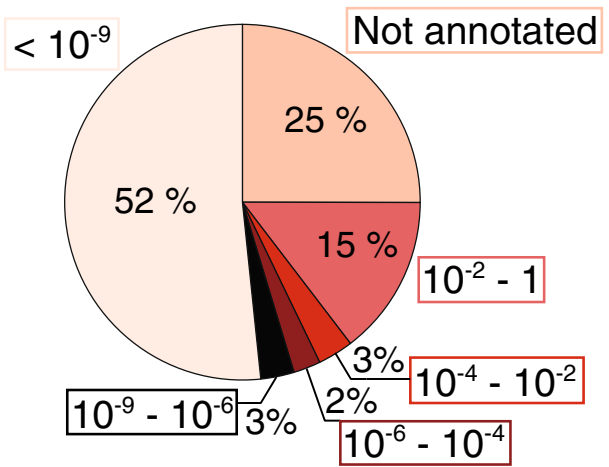

Fig. 2 Statistics from the annotation of predicted proteins using BLASTp. a Length distribution of the 9437 predicted proteins. Similarity (in \%) b and Evalues $\mathbf{c}$ of BLASTp hits to annotated proteins in the UniprotKB/Swiss-prot database

was performed with Blast2GO which divided the annotated proteins into 36 functional groups representing the categories biological process, cellular component and molecular function (Additional file 7).

\section{Carbohydrate-active enzymes in $M$. cinnamomea}

A total of 301 CAZy domains were found, among which were 137 GHs, 62 GTs, 4 PLs, 24 CEs, 42 AAs and 32
CBMs from a total of 108 different families (Table 1, Additional file 8). A number of fungal species were chosen as a comparison to the CAZyme repertoire of M. cinnamomea (a phylogenetic tree showing their evolutionary relation can be found in Additional file 9), including wellknown plant cell wall degraders from Ascomycetes and Basidiomycetes. The importance of complex carbohydrates as nutrients for M. cinnamomea is apparent when its CAZyme content is compared to the yeasts Kluyveromyces lactis, Saccharomyces cerevisiae and Yarrowia lipolytica, which have only about a third of the number of total CAZymes of M. cinnamomea and which primarily consume monosaccharides. Among fungi that utilise plant cell walls, the Ascomycetes Neurospora crassa and Myceliophthora thermophila, as well as the Basidiomycete Phanerochaete chrysosporium and the Zygomycete Rhizopus oryzae contain very similar numbers of CAZymes in their genomes to M. cinnamomea (Table 1). The distribution of CAZyme members across the GH families was quite different, however, with for instance $R$. oryzae [48], a known pectin degrader, possessing 18 GH28 family members, while M. cinnamomea has none (Additional file 8). Phanerochaete chrysosporium has five GH28 members, and M. thermophila has two, and both showed growth on pectin, in contrast to M. cinnamomea (Fig. 1c). Myceliophthora thermophila (thermophile) and $N$. crassa (mesophile) have similar distributions of CAZy families to $M$. cinnamomea in most categories, with the exception of the CBM1 family, where $M$. cinnamomea has only one member, and $N$. crassa and $M$. thermophila have 19 and 16, respectively (Additional file 8). Fungal species phylogenetically closer to M. cinnamomea, such as Aspergillus niger, Aspergillus nidulans, Aspergillus. oryzae and Penicillium chrysogenum, also share a similar CAZy family distribution with $M$. cinnamomea, but possess roughly twice the number of members in many GH families, such as GH2, 5, 11, 12, 13 and 43. However, M. cinnamomea possesses a comparatively high number of AAs and is especially enriched in families AA7, 9 and 11 .

The concerted action of members from various CAZy families is required for the efficient degradation of plant cell wall polymers. For example, $\beta$-1,4-endoglucanases, cellobiohydrolases, $\beta$-glucosidases and lytic polysaccharide monooxygenases (LPMOs) are needed for the deconstruction of cellulose [49]. These types of enzymes have fungal representatives in the nine CAZy families GH1, 3, 5, 6, 7, 12 and 45, and AA9 and 10. Putative candidates for all four cellulase types spanning eight different CAZy families were found in the M. cinnamomea FCH 10.5 genome, indicating that the fungus is theoretically capable of converting cellulose into monosaccharides (Additional file 8), contrasting the poor growth observed on plates containing Avicel or CMC as the only carbon source (Fig. 1c). 
Table 1 Comparison of the numbers of CAZymes in M. cinnamomea with those in other fungi

\begin{tabular}{|c|c|c|c|c|c|c|c|c|}
\hline Phylum & Species & GH & GT & PL & $\mathrm{CE}$ & $A A$ & CBM & All \\
\hline \multirow[t]{16}{*}{ ASC } & Yarrowia lipolytica ${ }^{a}$ & 42 & 45 & 0 & 1 & 10 & 8 & 106 \\
\hline & Saccharomyces cerevisiae ${ }^{a}$ & 45 & 65 & 0 & 2 & 6 & 15 & 133 \\
\hline & Kluyveromyces lactis ${ }^{\mathrm{a}}$ & 47 & 63 & 0 & 1 & 0 & 11 & 122 \\
\hline & Arthrobotrys oligospora ${ }^{a}$ & 205 & 87 & 15 & 30 & 33 & 180 & 550 \\
\hline & Malbranchea cinnamomea ${ }^{b}$ & 137 & 62 & 4 & 24 & 42 & 32 & 301 \\
\hline & Penicillium chrysogenum ${ }^{a}$ & 222 & 103 & 9 & 22 & 22 & 51 & 429 \\
\hline & Aspergillus nidulans ${ }^{\mathrm{a}}$ & 264 & 92 & 21 & 31 & 33 & 44 & 485 \\
\hline & Aspergillus niger ${ }^{a}$ & 253 & 121 & 8 & 23 & 68 & 55 & 528 \\
\hline & Aspergillus oryzae a & 307 & 117 & 23 & 29 & 30 & 37 & 543 \\
\hline & Leptosphaeria maculans $^{\mathrm{a}}$ & 220 & 98 & 19 & 33 & 33 & 53 & 456 \\
\hline & Thielavia terrestris $^{\mathrm{a}}$ & 212 & 91 & 4 & 28 & 58 & 80 & 473 \\
\hline & Myceliophthora thermophila & 195 & 87 & 8 & 28 & 50 & 50 & 418 \\
\hline & Podospora anserina ${ }^{\mathrm{a}}$ & 213 & 92 & 8 & 41 & 105 & 104 & 563 \\
\hline & Neurospora crassa ${ }^{a}$ & 174 & 78 & 4 & 22 & 35 & 42 & 355 \\
\hline & Magnaporthe grisea ${ }^{\mathrm{a}}$ & 265 & 105 & 4 & 52 & 92 & 114 & 632 \\
\hline & Fusarium graminearum ${ }^{\mathrm{a}}$ & 253 & 110 & 21 & 45 & 72 & 87 & 588 \\
\hline \multirow[t]{6}{*}{ BAS } & Rhodosporidium toruloides $^{\mathrm{a}}$ & 75 & 101 & 4 & 10 & 17 & 11 & 218 \\
\hline & Sporisorium reilianum ${ }^{\mathrm{a}}$ & 104 & 66 & 3 & 12 & 21 & 6 & 212 \\
\hline & Schizophyllum commune $e^{\mathrm{c,d}}$ & 237 & 77 & 5 & 40 & 70 & 39 & 468 \\
\hline & Piriformospora indica ${ }^{\mathrm{a}}$ & 206 & 73 & 16 & 45 & 57 & 141 & 538 \\
\hline & Phanerochaete chrysosporium ${ }^{\text {eff }}$ & 170 & 70 & 1 & 20 & 81 & 71 & 413 \\
\hline & Postia placenta ${ }^{g, h}$ & 174 & 102 & 2 & 22 & 22 & 22 & 344 \\
\hline ZYG & Rhizopus oryzae $e^{i, j}$ & 123 & 145 & 6 & 48 & 10 & 38 & 370 \\
\hline OOM & Phytophthora infestans ${ }^{a}$ & 283 & 157 & 67 & 21 & 0 & 37 & 565 \\
\hline
\end{tabular}

ASC Ascomycota, BAS Basidiomycota, ZYG Zygomycota, OOM Oomycota

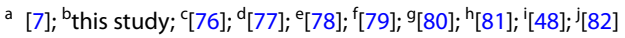

Closer inspection of the CAZy families involved in the hydrolysis of other plant cell wall polymers revealed that $M$. cinnamomea appears particularly well equipped for the degradation of xylan and chitin. In addition, the fungus probably possesses the genetic repertoire necessary for the deconstruction of xyloglucan, glucomannan and starch (Additional file 8). Surprisingly, no predicted $\alpha-1,6-$ galactosidase was found in the genome, even though $M$. cinnamomea grew well on locust bean galactomannan (Fig. 1c), suggesting that other enzymes might be involved in hydrolysis of this polymer. Regarding pectin, no proteins harbouring a GH28 domain were found to be present in the genome. The CAZy family GH28 contains pectindegrading activities such as rhamnogalacturonan hydrolase, polygalacturonase, galacturan 1,4- $\alpha$-galacturonidase, exo-poly- $\alpha$-galacturonosidase and rhamnogalacturonan hydrolase [50]. However, pectate/pectin lyases (family PL1), a rhamnogalacturonan lyase (family PL4), a pectate disaccharide lyase (family PL3) and a rhamnoglacturonyl hydrolase (family GH105) were found, as well as several pectin esterases (families CE8 and 12) (Additional file 8).

\section{Multimodular CAZymes in the genome of $M$. cinnamomea} CAZymes frequently exist as modular enzymes containing multiple CAZy domains, most often as a combination of a catalytic domain and a CBM. On average, $40 \%$ of fungal cellulases and hemicellulases are modular enzymes where the catalytic domain is connected to a non-catalytic CBM, to prolong contact with target polysaccharides [51, 52]. Twenty-one genes were found in $M$. cinnamomea that contained two or more predicted CAZy domains (Fig. 3). Of these, 13 genes had one catalytic domain in addition to one, two or three CBMs. Seven genes had a combination of two or three catalytic domains and one gene was found to contain four CBM50 domains. Although a CBM1 domain is fairly abundant in other fungal species, in particular in cellulase enzymes [52], in M. cinnamomea $\mathrm{FCH} 10.5$ this domain could only be detected in one gene, fused to a GH10 domain. In addition to multimodular CAZymes, eight genes were found for which searches in the dbCAN and the NCBI CDD database resulted in hits for CBMs, but not for conserved catalytic domains (Fig. 3). 


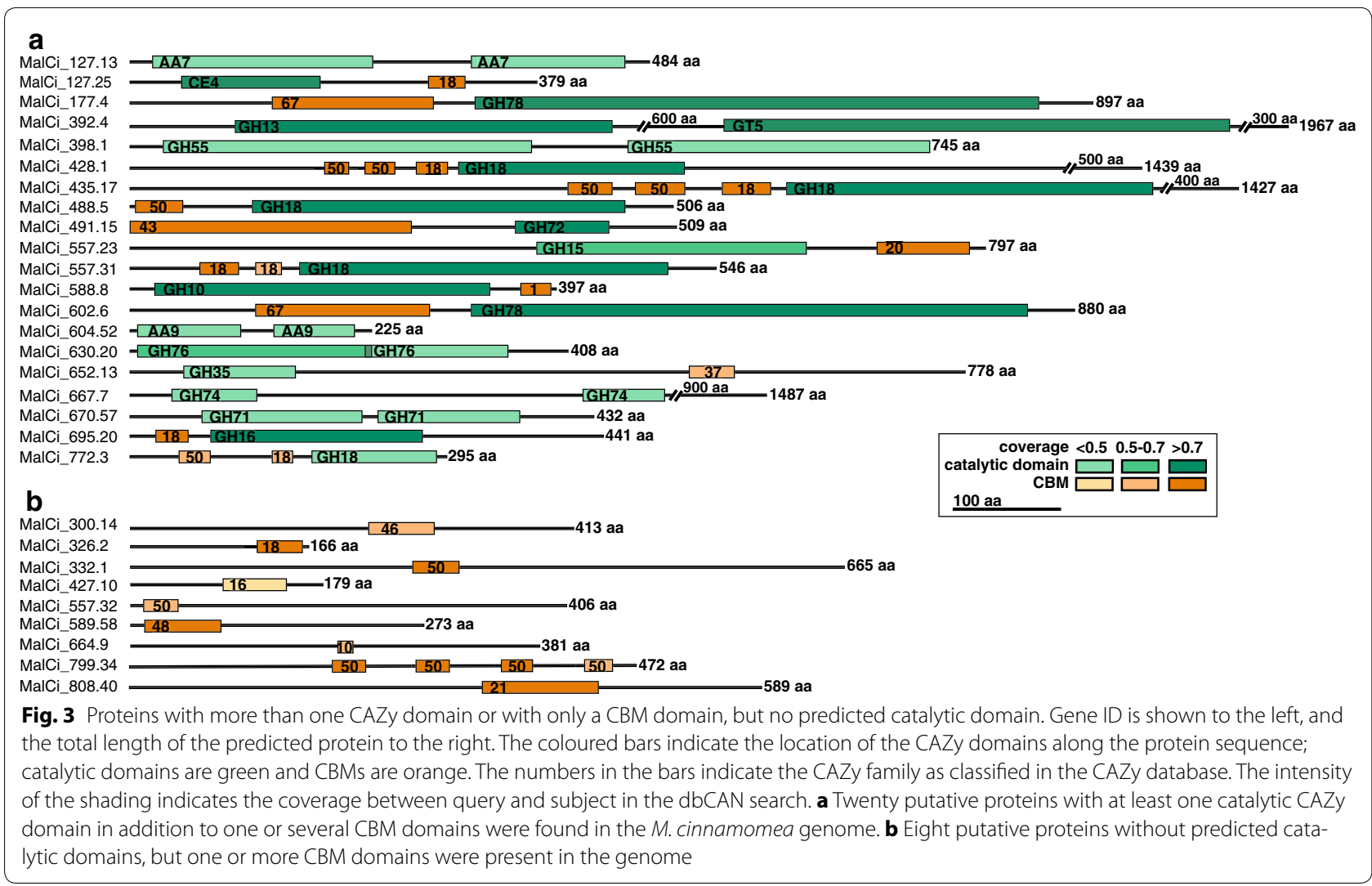

\section{CAZymes expressed during growth on glucose, wheat bran and xylan}

To investigate how gene expression is influenced by growth on an easily metabolised carbon source, where mostly constitutive genes are predicted to be expressed compared to growth on a more complex carbon sources, RNAseq analysis was conducted on $M$. cinnamomea cultivated on glucose, wheat bran and beechwood xylan. Beechwood xylan, comprising a xylan backbone with 4-O-methyl glucuronic acid side groups, was chosen to study the expression of genes specific for hardwood hemicellulose degradation, while wheat bran was chosen as a cereal substrate of higher complexity, predicted to induce the expression of genes encoding a variety of CAZymes. A total of 266 distinct transcripts containing CAZy domains (of the 271 CAZy domain-containing genes found in the genome) were identified in cultures grown on at least one of the substrates (Additional file 10). Eight and 61 of these genes, respectively, contained CBM and GT domains. The remaining 197 transcripts were classified into $47 \mathrm{GH}, 6 \mathrm{CE}, 10 \mathrm{AA}$ and $3 \mathrm{PL}$ families, respectively. Most transcripts were transcribed on all three carbon sources at varying levels.

Many fungal CAZymes involved in the degradation of biomass are secreted into the environment. The 40 most highly expressed genes during growth on wheat bran and xylan, predicted to contain both a secretion signal and one or more CAZy domains, are shown in Table 2 (for a complete list, see Additional file 10). A high percentage of these were found to encode putative enzymes involved in plant biomass deconstruction, such as the degradation of xylan or xyloglucan (GH2, 5, 10, 11, 16 and 74, CE5), $\beta$-glucan (GH5, 6, $7,16,17,55,72,74$ and 132), cellulose (AA9, GH6, GH74), starch (GH13) or pectin (PL1, PL3). The most highly expressed transcript of a secreted CAZyme on wheat bran, however, was the putative GH72 $\beta$-1,3glucanosyltransglycosylase MalCi_235.14. Transcripts of this gene were also highly abundant during growth on xylan. GH72 enzymes are known to be involved in elongation and remodelling of the $\beta$-1,3-glucan of the fungal cell wall [53]. Thus, MalCi_235.14 is not likely to be involved in plant biomass degradation, but may be important for hyphal growth during an abundance of nutrients. Similarly, several putative chitinase-encoding genes (GH18) were also highly expressed on wheat bran and xylan. Chitinases play a role in many aspects of the fungal life cycle, including cell wall remodelling and degradation of exogenous chitin as a nutrient source [54]. 
Table 2 The $\mathbf{4 0}$ most highly expressed genes encoding putatively secreted CAZymes in M. cinnamomea FCH 10.5

\begin{tabular}{|c|c|c|c|}
\hline Gene ID & $\mathrm{fpkm}^{\mathrm{a}}$ & Domain $^{b}$ & Putative function ${ }^{c}$ \\
\hline \multicolumn{4}{|l|}{ a) Wheat bran } \\
\hline MalCi_235.14 & 3225 & $\mathrm{GH} 72$ & $\begin{array}{l}\beta 1,3- \\
\text { glucanosyltransferase }\end{array}$ \\
\hline MalCi_655.10 & 2516 & $\mathrm{GH} 2$ & $\beta$-galactosidase \\
\hline MalCi_664.5 & 2102 & CE5 & Cutinase \\
\hline MalCi_372.12 & 1816 & $\mathrm{GH} 17$ & $\beta 1,3$-glucosidase \\
\hline MalCi_266.5 & 1377 & $\mathrm{GH} 17$ & $\beta 1,3$-glucosidase \\
\hline MalCi_695.20 & 1325 & GH16-CBM18 & Chitinase \\
\hline MalCi_179.14 & 1310 & GH132 & $\beta$-glucosidase \\
\hline MalCi_724.6 & 1052 & AA11 & LPMO \\
\hline MalCi_790.1 & 848 & $\mathrm{GH} 47$ & a1,2-mannosidase \\
\hline MalCi_808.35 & 712 & CE5 & Cutinase \\
\hline MalCi_670.57 & 658 & GH71-GH71 & endo-a1,3-glucanase \\
\hline MalCi_652.31 & 589 & GH132 & $\beta 1,3$-glucanase \\
\hline MalCi_489.39 & 511 & GH5 & endo- $\beta 1$,4-glucanase \\
\hline MalCi_460.6 & 409 & $\mathrm{GH} 7$ & Cellobiohydrolase \\
\hline MalCi_646.16 & 406 & GH5 & endo- $\beta 1,4-m a n n o s i d a s e$ \\
\hline MalCi_757.11 & 393 & GH16 & $\begin{array}{l}\text { endo- } \beta 1,3 / 1,4- \\
\text { glucanase }\end{array}$ \\
\hline MalCi_655.13 & 259 & $\mathrm{GH} 13$ & a-amylase \\
\hline MalCi_617.15 & 227 & $\mathrm{GH} 11$ & endo- $\beta 1,4$-xylanase \\
\hline MalCi_646.9 & 199 & AA6 & $\begin{array}{l}\text { 1,4-benzoquinone } \\
\text { reductase }\end{array}$ \\
\hline MalCi_780.39 & 197 & GH6 & Cellobiohydrolase \\
\hline MalCi_624.16 & 191 & GH16 & Glucanase \\
\hline MalCi_504.4 & 176 & GH5 & endo- $\beta 1$,4-mannosidase \\
\hline MalCi_739.16 & 172 & AA9 & LPMO \\
\hline MalCi_769.3 & 172 & AA11 & LPMO \\
\hline MalCi_091.4 & 170 & $\mathrm{GH} 20$ & $\beta$-hexosaminidase \\
\hline MalCi_695.4 & 159 & CE5 & Cutinase \\
\hline MalCi_618.6 & 147 & PL1 & Pectate lyase \\
\hline MalCi_667.7 & 144 & GH74-GH47 & endo- $\beta 1$,4-glucanase \\
\hline MalCi_652.77 & 123 & PL3 & Pectate lyase \\
\hline MalCi_435.17 & 122 & $\begin{array}{l}\text { GH18-CBM50- } \\
\text { CBM50-CBM18 }\end{array}$ & Chitinase \\
\hline MalCi_700.10 & 110 & GH65 & a,a-trehalase \\
\hline MalCi_528.12 & 103 & $\mathrm{GH} 18$ & Chitinase \\
\hline MalCi_123.8 & 98 & AA9 & LPMO \\
\hline MalCi_398.1 & 94 & GH55-GH55 & $\beta 1,3$-glucosidase \\
\hline MalCi_219.18 & 92 & PL1 & Pectate lyase \\
\hline MalCi_177.6 & 88 & AA1 & Multicopper oxidase \\
\hline MalCi_787.11 & 86 & AA7 & $\begin{array}{l}\text { Glucooligosaccharide } \\
\text { oxidase }\end{array}$ \\
\hline MalCi_534.8 & 82 & $\mathrm{GH} 7$ & endo- $\beta 1$,4-glucanase \\
\hline MalCi_596.9 & 82 & AA6 & $\begin{array}{l}\text { 1,4-benzoquinone } \\
\text { reductase }\end{array}$ \\
\hline MalCi_675.5 & 77 & CE5 & Cutinase \\
\hline \multicolumn{4}{|c|}{ b) Beechwood xylan } \\
\hline MalCi_646.9 & 4912 & AA6 & $\begin{array}{l}\text { 1,4-benzoquinone } \\
\text { reductase }\end{array}$ \\
\hline
\end{tabular}

Table 2 continued

\begin{tabular}{|c|c|c|c|}
\hline Gene ID & $\mathrm{fpkm}^{\mathrm{a}}$ & Domain $^{b}$ & Putative function ${ }^{c}$ \\
\hline MalCi_235.14 & 3648 & $\mathrm{GH} 72$ & $\begin{array}{l}\beta 1,3- \\
\quad \text { glucanosyltransferase }\end{array}$ \\
\hline MalCi_617.15 & 3059 & $\mathrm{GH} 11$ & endo- $\beta 1,4-x y l a n a s e$ \\
\hline MalCi_372.12 & 1951 & $\mathrm{GH} 17$ & $\beta 1,3$-glucosidase \\
\hline MalCi_266.5 & 1849 & $\mathrm{GH} 17$ & $\beta 1,3$-glucosidase \\
\hline MalCi_655.10 & 1667 & $\mathrm{GH} 2$ & $\beta$-galactosidase \\
\hline MalCi_179.14 & 1368 & GH132 & $\beta$-glucosidase \\
\hline MalCi_670.57 & 1092 & GH71-GH71 & endo-a1,3-glucanase \\
\hline MalCi_790.1 & 943 & $\mathrm{GH} 47$ & a1,2-mannosidase \\
\hline MalCi_724.6 & 734 & AA11 & LPMO \\
\hline MalCi_695.20 & 663 & GH16-CBM18 & Chitinase \\
\hline MalCi_769.3 & 624 & AA11 & LPMO \\
\hline MalCi_435.17 & 425 & $\begin{array}{l}\text { GH18-CBM50- } \\
\text { CBM50-CBM18 }\end{array}$ & Chitinase \\
\hline MalCi_757.11 & 419 & GH16 & $\begin{array}{l}\text { endo- } \beta 1,3 / 1,4- \\
\text { glucanase }\end{array}$ \\
\hline MalCi_652.31 & 223 & GH132 & $\beta 1,3$-glucanase \\
\hline MalCi_219.18 & 211 & PL1 & Pectate lyase \\
\hline MalCi_618.6 & 188 & PL1 & Pectate lyase \\
\hline MalCi_588.8 & 174 & GH10-CBM1 & endo- $\beta 1,4-x y l a n a s e$ \\
\hline MalCi_652.77 & 170 & PL3 & Pectate lyase \\
\hline MalCi_700.10 & 149 & GH65 & a,a-trehalase \\
\hline MalCi_646.16 & 144 & GH5 & endo- $\beta 1,4-m a n n o s i d a s e$ \\
\hline MalCi_596.9 & 134 & AA6 & $\begin{array}{l}\text { 1,4-benzoquinone } \\
\text { reductase }\end{array}$ \\
\hline MalCi_298.13 & 133 & GH18 & Chitinase \\
\hline MalCi_398.1 & 129 & GH55-GH55 & $\beta 1,3$-glucosidase \\
\hline MalCi_808.35 & 128 & CE5 & Cutinase \\
\hline MalCi_667.7 & 116 & GH74-GH47 & endo- $\beta 1,4$-glucanase \\
\hline MalCi_460.6 & 111 & $\mathrm{GH} 7$ & Cellobiohydrolase \\
\hline MalCi_795.24 & 81 & $\mathrm{GH} 2 \mathrm{O}$ & $\beta$-hexosaminidase \\
\hline MalCi_666.7 & 81 & $\mathrm{GH} 24$ & Lysozyme \\
\hline MalCi_091.4 & 73 & $\mathrm{GH} 2 \mathrm{O}$ & $\beta$-hexosaminidase \\
\hline MalCi_528.12 & 69 & $\mathrm{GH} 18$ & Chitinase \\
\hline MalCi_695.4 & 68 & CE5 & Cutinase \\
\hline MalCi_739.16 & 67 & AA9 & LPMO \\
\hline MalCi_780.39 & 62 & GH6 & Cellobiohydrolase \\
\hline MalCi_664.5 & 55 & CE5 & Cutinase \\
\hline MalCi_682.37 & 54 & $\mathrm{GH} 2$ & exo- $\beta$-glucosaminidase \\
\hline MalCi_177.6 & 53 & AA1 & Multicopper oxidase \\
\hline MalCi_624.16 & 53 & GH16 & Glucanase \\
\hline MalCi_381.4 & 49 & GT31 & $\begin{array}{l}\text { Chondroitin sulphate } \\
\text { synthase }\end{array}$ \\
\hline MalCi_787.11 & 47 & AA7 & $\begin{array}{l}\text { Glucooligosaccharide } \\
\text { oxidase }\end{array}$ \\
\hline
\end{tabular}

a Normalised expression level of transcripts, average of two biological replicates

b CAZy domain as predicted by dbCAN 5.0

c Putative function deduced from first hit in BLASTp search against UniprotKB/ Swiss-prot database 


\section{Differential gene expression on wheat bran and xylan}

To obtain information on how gene expression is influenced during growth on wheat bran and beechwood xylan, in comparison to glucose, a differential expression analysis was conducted. Using a $\log 2$ increase of at least 1 (i.e. a twofold enrichment) in relative transcript abundance as the significant threshold (adjusted $p$ value $<0.05$ ), 438 and 150 unique sequences were considered significantly more abundant in the samples grown on wheat bran and beechwood xylan, respectively, compared to glucose. Among the differentially expressed genes, many putative CAZymes that act on biopolymers, were found (Fig. 4, Additional file 11). When cultivated on wheat bran, the most highly upregulated transcript containing a CAZy domain (27.9 times more abundant than on glucose) stemmed from gene MalCi_604.52, comprising two predicted AA9 domains. Three other AA9 s were also highly upregulated (MalCi_739.16, MalCi_638.10, MalCi_639.3), as well as genes typically associated with cellulose degradation (GH1: MalCi_790.16; GH3: MalCi_7.3, MalCi_247.3, MalCi_817.36; GH5: MalCi_646.16, MalCi_748.9). Although fewer celluloseactive genes were upregulated in $M$. cinnamomea when grown on xylan, transcripts of two AA9 s (MalCi_780.38, MalCi_638.10) and one GH5 (MalCi_748.9) were still more abundant than when the fungus was cultivated on glucose (Fig. 4). Other genes encoding putative AA family members, apart from AA9 s, were also upregulated: a putative 1,4-benzoquinone reductase (AA6, MalCi_646.9), an AA11 LPMO (MalCi_762.12) and two AA3 oxidases (AA3, MalCi_414.1, MalCi_756.13), as well as two AA7 domain-containing genes (MalCi_787.11, MalCi_806.21).

Several genes encoding putative hemicellulose-active enzymes were upregulated after cultivation on both wheat bran and xylan; the most highly upregulated gene encoding a GH11 putative endo- $\beta 1,4$-xylanase (MalCi_617.15) (Fig. 4). Its transcripts were 301.8 times more abundant during growth on xylan and 22.79 more abundant during growth on wheat bran, respectively, compared to glucose. Four additional putative endo$\beta 1,4$-xylanases were more abundant on xylan, compared to glucose: MalCi_210.5 (GH10), MalCi_551.3 (GH10), MalCi_551.2 (GH10) and MalCi_588.8 (GH10-CBM1).
Of these, only MalCi_551.3 was also significantly upregulated during growth on wheat bran. The expression of two putative CE5 genes (encoding acetyl xylan esterases or cutinases) was strongly increased during growth on wheat bran with MalCi_664.5 and MalCi_675.5 being 23.7 times and 10.1 times, respectively, more abundant on wheat bran than on glucose. Furthermore, the following genes, which encode accessory xylanolytic enzymes that liberate side groups from the main chain, were differently expressed during cultivation on wheat bran and xylan, compared to glucose: three CE4 putative acetyl xylan esterases (MalCi_634.13, MalCi_599.21, MalCi_520.4); a GH43 putative $\beta$-xylosidase (MalCi_519.11) and a GH43 putative $\beta$-xylosidase or $\alpha$-L-arabinofuranosidase (MalCi_728.6), which remove xylose or arabinose units from the non-reducing end; a GH67 putative $\alpha$-glucuronidase (MalCi_603.16), which cleaves glucuronic acid side groups from xylans; and two $\mathrm{GH} 2$ putative $\beta$-galactosidases (MalCi_655.10, MalCi_200.2).

Hemicelluloses are crosslinked to lignin via ferulic acid or glucuronic acid ester linkages [55]. Ferulic acid esters are particularly abundant in grasses, and accordingly, a gene encoding a putative feruloyl esterase (CE1, MalCi_780.22) was upregulated 7.6 times on wheat bran. Transcripts of a putative glucuronoyl esterase (CE15, MalCi_534.2), which is thought to hydrolyse the ester linkages between lignin and 4-O-methyl-D-glucuronic acid side chains of xylan [56], were more abundant on both wheat bran (4.1 times) and xylan (27.7 times) than on glucose. The expression of several genes with predicted secretion signals but lacking known function by BLAST were upregulated on either wheat bran, xylan or both. MalCi_132.2 (xylan: 15.1-fold; wheat bran: 62.2fold), MalCi_565.14 (xylan: 7.6-fold; wheat bran: 10.5fold), MalCi_610.8 (xylan: 3.3-fold; wheat bran: 8.8-fold), MalCi_521.23 (wheat bran: 16.4-fold), MalCi_666.6 (wheat bran: 7.0-fold) and MalCi_398.7 (wheat bran: 4.3fold). In addition, one gene comprising a CBM9 as the only identified domain was 28.5 -fold more abundant on wheat bran, compared to glucose. Of the 87 genes, whose transcripts were considered significantly more abundant in M. cinnamomea after cultivation on both xylan and wheat bran, nine comprised predicted CAZy domains and eight of those are likely involved in biopolymer

(See figure on next page.)

Fig. 4 Differentially expressed CAZymes during cultivation on xylan and wheat bran. a Fold change of gene expression during cultivation on xylan and wheat bran, compared to glucose. Upregulated genes (i.e. transcripts more abundant on xylan and/or wheat bran) are shaded green, downregulated genes (i.e. transcripts more abundant on glucose) are shaded red. b Fold change of transcripts more abundant during growth on xylan than on wheat bran (blue shading). c Fold change of transcripts more abundant during growth on wheat bran than on xylan (yellow shading). Shading is stronger for higher fold changes for all cases. Transcripts were considered significantly differentially expressed when fold change was at least two $(p \leq 0.05)$. Sec., genes encoding putatively secreted proteins. The prediction was done with two algorithms, SignalP 4.1 (black circles signify proteins with recognised signal peptide), and WOLF PSORT (blue circles signify proteins predicted to be secreted) 


\begin{tabular}{|c|c|c|c|c|c|c|c|c|}
\hline \multirow[b]{2}{*}{ Gene ID } & \multirow{2}{*}{\multicolumn{2}{|c|}{ Sec. CAZy domains }} & \multirow[b]{2}{*}{ Putative function } & \multicolumn{2}{|c|}{$\mathbf{a}$} & \multirow{2}{*}{$\begin{array}{r}\mathbf{b} \\
\text { Xylan }\end{array}$} & C & \\
\hline & & & & Xylan & $\begin{array}{c}\text { Wheat } \\
\text { bran }\end{array}$ & & $\begin{array}{c}\text { Wheat } \\
\text { bran }\end{array}$ & Polymer \\
\hline MalCi_617.15 & - & GH11 & endo- $\beta 1,4$-xylanase & 301.8 & 22.8 & 13.3 & & $\mathrm{x}$ \\
\hline MalCi_210.5 & - & GH10 & endo- $\beta 1,4$-xylanase & 35.2 & & 10.5 & & $\mathrm{x}$ \\
\hline MalCi_634.13 & & CE4 & Acetyl xylan esterase & 31.4 & 3.3 & 9.4 & & $x$ \\
\hline MalCi_638.10 & & AA9 & LPMO & 31.3 & 15.2 & & & c \\
\hline MalCi_534.20 & - & CE15 & 4-O-methyl-glucuronoyl methylesterase & 27.7 & 4.1 & 6.8 & & $\mathrm{x}$ \\
\hline MalCi_646.9 & & AA6 & 1,4-benzoquinone reductase & 26.0 & & 23.9 & & \\
\hline MalCi_551.3 & & GH10 & endo- $\beta 1,4$-xylanase & 24.6 & 5.7 & 4.3 & & $\mathrm{x}$ \\
\hline MalCi_551.2 & & $\mathrm{GH} 10$ & endo- $\beta 1,4$-xylanase & 14.4 & & 3.9 & & $\mathrm{x}$ \\
\hline MalCi_739.16 & - & AA9 & LPMO & 7.8 & 19.7 & & & c \\
\hline MalCi_519.11 & & $\mathrm{GH} 43$ & $\beta$-Xylosidase/a-L-arabinofuranosidase & 6.6 & & 5.0 & & $X, P, X G$ \\
\hline MalCi_603.16 & - & GH67 & a-glucuronidase & 6.0 & & 4.1 & & $\mathrm{x}$ \\
\hline MalCi_748.9 & - & GH5 & endo- $\beta 1,4$-glucanase & 5.2 & 12.8 & & 2.5 & $C, X G$ \\
\hline MalCi_728.6 & & $\mathrm{GH} 43$ & $\beta$-Xylosidase/a-L-arabinofuranosidase & 5.0 & & 2.7 & & $X, P, X G$ \\
\hline MalCi_655.10 & - & GH2 & $\beta$-galactosidase & 4.8 & 7.6 & & & $\mathrm{X}, \mathrm{XG}, \mathrm{M}, \mathrm{P}$ \\
\hline MalCi_589.65 & & CE1 & $\alpha / \beta$-hydrolase & 4.6 & & 2.2 & & $X, P$ \\
\hline MalCi_148.8 & - & GH25 & Lysozyme & 4.5 & 3.9 & & & \\
\hline MalCi_775.5 & & $\mathrm{GH} 31$ & $a$-xylosidase & 3.8 & & 2.4 & & \\
\hline MalCi_435.17 & & $\begin{array}{l}\text { GH18-CBM50- } \\
\text { CBM0-CBM18 }\end{array}$ & Chitinase & 3.7 & & 2.8 & & $\mathrm{Ch}$ \\
\hline MalCi_588.8 & - & GH10-CBM1 & endo- $\beta 1,4$-xylanase & 2.8 & & 3.0 & & $x$ \\
\hline MalCi_332.5 & & GH31 & $a$-xylosidase & 2.6 & & 4.4 & & \\
\hline MalCi_604.52 & - & AA9-AA9 & LPMO & & 28.0 & & 12.9 & $\mathrm{c}$ \\
\hline MalCi_664.5 & - & CE5 & Cutinase & & 22.7 & & 31.9 & $\mathrm{Cu}$ \\
\hline MalCi_91.4 & $\bullet$ & GH2O & $\beta$-hexosaminidase & & 12.5 & & 2.4 & $\mathrm{Ch}$ \\
\hline MalCi_231.5 & & CE1 & $\alpha / \beta$ hydrolase & & 10.2 & & 8.2 & $X, P$ \\
\hline MalCi_675.5 & - & CE5 & Cutinase & & 10.1 & & 16.8 & $\mathrm{Cu}$ \\
\hline MalCi_666.7 & & GH24 & Lysozyme & & 7.7 & & & \\
\hline MalCi_780.22 & - & CE1 & Feruloyl esterase & & 7.6 & & 7.2 & $X, P$ \\
\hline MalCi_589.51 & & GH16 & endo- $\beta 1,4$-glucanase & & 6.4 & & 2.3 & $X G, C$ \\
\hline MalCi_762.12 & & AA11 & LPMO & & 6.2 & & & $\mathrm{Ch}$ \\
\hline MalCi_599.21 & - & CE4 & Chitin deacetylase & & 5.8 & & & $\mathrm{Ch}$ \\
\hline MalCi_589.58 & & CBM48 & - & & 4.8 & & 3.4 & \\
\hline MalCi_639.3 & 0 & AA9 & LPMO & & 4.4 & & 2.3 & \\
\hline MalCi_809.19 & 0 & GH12 & endo- $\beta 1,4$-glucanase & & 4.3 & & 8.5 & $\mathrm{XG}, \mathrm{M}, \mathrm{C}$ \\
\hline MalCi_528.57 & & GT71 & a1,3-mannosyltransferase & & 4.2 & & & \\
\hline MalCi_596.13 & 0 & GH18 & Chitinase & & 4.1 & & 2.0 & $\mathrm{Ch}$ \\
\hline MalCi_806.21 & - & AA7 & Glucooligosaccharide oxidase & & 4.0 & & 9.3 & \\
\hline MalCi_200.2 & & GH2 & endo- $\beta 1,4$-mannosidase & & 3.7 & & 3.8 & M \\
\hline MalCi_520.4 & & CE4 & Acetylxylan esterase & & 3.5 & & & $\mathrm{x}$ \\
\hline MalCi_414.1 & & AA3 & Oxidase & & 3.3 & & 2.4 & \\
\hline MalCi_44.1 & & GH72 & $\beta 1,3$-glucanosyltransferase & & 3.3 & & & \\
\hline MalCi_787.11 & • & AA7 & Glucooligosaccharide oxidase & & 3.3 & & & \\
\hline MalCi_646.16 & - & GH5 & endo- $\beta 1,4$-mannosidase & & 3.2 & & 2.7 & M \\
\hline MalCi_783.26 & - & GH92 & a-glycosidase & & 3.0 & & 2.8 & \\
\hline MalCi_790.16 & & $\mathrm{GH} 1$ & $\beta$-glucosidase & & 2.9 & & 2.6 & c \\
\hline MalCi_652.31 & - & GH132 & $\beta 1,3$-glucanase & & 2.9 & & 2.5 & \\
\hline MalCi_-7.3 & & GH3 & $\beta$-glucosidase & & 2.8 & & & c \\
\hline MalCi_624.16 & 0 & GH16 & endo- $\beta 1,4$-glucanase & & 2.6 & & 3.3 & $\mathrm{XG}, \mathrm{C}$ \\
\hline MalCi_817.36 & & $\mathrm{GH} 3$ & $\beta$-glucosidase & & 2.4 & & 2.8 & c \\
\hline MalCi_247.3 & & $\mathrm{GH} 3$ & $\beta$-glucosidase & & 2.4 & & 2.3 & c \\
\hline MalCi_756.13 & & AA3 & Oxidase & & 2.3 & & 3.1 & \\
\hline MalCi_489.39 & - & GH5 & endo- $\beta 1,4$-glucanase & 9.9 & & & 3.5 & $X G, M, C$ \\
\hline MalCi_177.4 & & GH78-CBM67 & $\beta$-glucosidase & & 5.3 & & & C \\
\hline MalCi_615.33 & & AA3 & Dehydrogenase & 4.6 & 5.3 & & & \\
\hline MalCi_808.40 & & CBM21 & Phosphatase regulatory subunit & 2.6 & & & & \\
\hline MalCi_392.4 & - & GH13-GT5 & a1,3-glucan synthase & & 2.8 & & & \\
\hline MalCi_147.10 & & GH16 & Glycosidase & & 2.2 & & & $X G, C$ \\
\hline MalCi_219.18 & - & PL1 & Pectate lyase & & & 7.1 & & \\
\hline MalCi_519.11 & & $\mathrm{GH} 43$ & $\beta$-Xylosidase/a-L-arabinofuranosidase & & & 5.0 & & $X G, X, P$ \\
\hline MalCi_803.85 & & CE4 & Acetylxylan esterase & & & 3.0 & & $\mathrm{x}$ \\
\hline MalCi_728.6 & & $\mathrm{GH} 43$ & $\beta$-Xylosidase/a-L-arabinofuranosidase & & & 2.7 & & $X G, X, P$ \\
\hline MalCi_165.1 & - & $\mathrm{GH} 3$ & $\beta$-glucosidase & & & 2.1 & & c \\
\hline MalCi_775.6 & • & $\mathrm{GH} 3$ & $\beta$-glucosidase & & & 2.0 & & c \\
\hline MalCi_809.19 & 0 & $\mathrm{GH} 12$ & endo- $\beta 1,4$-glucanase & & & & 8.5 & $X G, M, C$ \\
\hline MalCi_808.35 & $\bullet$ & CE5 & Cutinase & & & & 6.5 & Cu \\
\hline MalCi_780.38 & - & AA9 & LPMO & & & & 6.5 & c \\
\hline MalCi_504.3 & & GH31 & $a$-xylosidase & & & & 5.5 & \\
\hline MalCi_460.6 & - & GH7 & endo- $\beta 1,4$-glucanase & & & & 3.6 & $\mathrm{XG}, \mathrm{C}$ \\
\hline MalCi_534.8 & • & GH7 & endo- $\beta 1,4$-glucanase & & & & 3.6 & $X G, C$ \\
\hline MalCi_504.4 & - & GH5 & endo- $\beta 1,4$-mannosidase & & & & 3.2 & M \\
\hline MalCi_780.39 & • & GH6 & endo- $\beta 1,4$-glucanase & & & & 3.0 & $X G, C$ \\
\hline MalCi_695.4 & - & CE5 & Cutinase & & & & 2.6 & $\mathrm{Cu}$ \\
\hline MalCi_602.6 & & GH78-CBM67 & a-L-rhamnosidase & & & & 2.4 & $\mathrm{P}$ \\
\hline MalCi_612.11 & & GH2 & $\beta$-galactosidase & & & & 2.3 & $\mathrm{X}, \mathrm{XG}, \mathrm{M}, \mathrm{P}$ \\
\hline MalCi_75.8 & & GH105 & Rhamnogalacturonyl hydrolase & & & & 2.3 & $\mathrm{P}$ \\
\hline MalCi_123.8 & 0 & AA9 & LPMO & & & & 2.2 & c \\
\hline MalCi_665.4 & 0 & AA5 & Oxidase & & & & 2.1 & \\
\hline MalCi_519.21 & 0 & AA11 & LPMO & & & & 2.0 & $\mathrm{Ch}$ \\
\hline
\end{tabular}


deconstruction (Fig. 4). Many genes were also differently expressed during growth on wheat bran compared to growth on xylan. In total, 355 transcripts were more abundant on xylan, and 410 more abundant on wheat bran (adjusted $p$ value $<0.05, \log 2 \geq 1$ ). Among these, 20 transcripts containing CAZy domains were upregulated during growth on xylan and 39 on wheat bran (Fig. 4, Additional file 11). The genes more abundantly expressed on xylan included many putative xylanases of the GH10 and GH11 families, while a wider variety of putative CAZymes was upregulated after growth on wheat bran, primarily AA9, GH1, 3 and 5 family members, as well as putative feruloyl esterases, acetylxylan esterases and cutinases of the CE1, 4 and 5 families, respectively. A gene set analysis of the genes found to be upregulated during growth of $M$. cinnamomea on wheat bran and xylan revealed that the following GO categories were most enriched: GO:0016798 (hydrolase activity, acting on glycosyl bonds), GO:0016491 (oxidoreductase activity), GO:0022857 (transmembrane transporter activity), GO:0005975 (carbohydrate metabolic process) and GO:0006629 (lipid metabolic process) (Additional file 12).

Far fewer genes were downregulated after growth on wheat bran (195) and xylan (34) compared to glucose (Additional file 11). Among the downregulated genes on wheat bran, four were identified that comprise CAZy domains: a gene encoding a GH16 putative glycosidase (MalCi_147.10), a GT5-GH13 multimodular putative cell wall $\alpha$-1,3-glucan synthase (MalCi_392.4), a GH78CBM67 putative $\beta$-glucosidase (MalCi_177.4) and an AA3 family protein (MalCi_615.33). On xylan, three putative CAZyme genes were downregulated: a gene comprising a CBM21 domain (MalCi_808.40), a gene encoding a GH5 putative $\beta$-1,4-glucanase ( $M a l C i$ _489.39) and the same gene encoding a AA3 protein that was also downregulated on wheat bran.

Transcriptional regulators, like $\mathrm{X} \ln \mathrm{R}$ from $A$. niger and CreA from $A$. nidulans, are known to be involved in fungal biomass turnover [57]. Two orthologues of $\mathrm{X} \ln R$, MalCi_741.50 and MalCi_792.36, were both expressed in M. cinnamomea FCH 10.5 at similar levels when it was grown on glucose, wheat bran or xylan (Additional file 11). Similarly, the expression of two genes encoding orthologues of the repressor CreA, MalCi_342.1 and MalCi_11.1, was not significantly different on the three substrates tested.

\section{Discussion}

In the present study, we have systematically explored the lignocellulolytic potential of the thermophilic fungus M. cinnamomea on a genomic level. The obtained information serves as a resource for detailed exploitation of its enzymes. We have performed a genomic analysis of the M. cinnamomea, strain FCH 10.5, an analysis of its transcriptional response when grown on beechwood xylan, wheat bran and glucose, and correlated the presence of putative CAZymes in the genome to its ability to grow on different carbohydrates. Our study shows that $M$. cinnamomea has an abundant repertoire of CAZy domaincontaining genes that are distributed over 108 different CAZy families, and has furthermore the genetic potential to degrade the majority of naturally occurring plant cell wall polysaccharides. M. cinnamomea (syn. M. pulchella var. sulfurea) has been isolated from soil, decaying vegetation and self-heating hay stacks all over the world [58], suggesting that the species is widely distributed in the environment, and that it has a significant role in plant biomass degradation. Several enzymes from M. cinnamomea that are targeting biopolymers have been studied and expressed in recent years [18-25; Additional file 1], and all of these enzymes were reported to have temperature optima between 45 and $80^{\circ} \mathrm{C}$.

In a phylogenetic analysis including several well-studied biomass degraders, $M$. cinnamomea was found to be evolutionary closer to Aspergillus and Penicillium species (order Eurotiales) than Myceliophthora or Neurospora species (order Sordariales) [17]. However, its repertoire of CAZymes is much more similar to the phylogenetically more distant species $M$. thermophila and $N$. crassa (Table 1). Closely related fungal species were shown to use different sets of enzymes to hydrolyse the same complex biomass [59], while species with considerable evolutionary distance can display a similar arsenal of CAZymes. A strong influence of the natural habitat on the capability of fungi to degrade biomass, i.e. their repertoire of specific enzymatic activities, could be a possible explanation. This hypothesis is supported by the findings that the thermophilic $M$. thermophila, which is, like $M$. cinnamomea, commonly found in compost, hay stacks and sun-heated soil [60], has a CAZyme repertoire more similar to that of $M$. cinnamomea than the phylogenetically closer mesophiles $A$. oryzae, $A$. niger, A. nidulans and $P$. chrysogenum (Additional files 8, 9).

The growth profile data as well as the measured enzyme activities were generally in good agreement with the repertoire of putative CAZymes found in the M. cinnamomea genome as well as in the transcriptome analysis. The preferred substrates of $M$. cinnamomea FCH 10.5 among the tested ones were beechwood xylan, cellobiose and starch (Fig. 1c), which correlated well with the presence of related CAZymes in the genome (Additional file 8). Good growth could also be observed on inulin, even though no putative invertase or inulinase genes were identified in the genome, similar to what has been observed in $R$. oryzae [48]. M. cinnamomea also grew 
well on locust bean gum (galactomannan with galactose residues on every fourth mannose), despite the apparent absence of genes encoding $\alpha$-1,6-galactosidases in its genome. As expected from the lack of genes encoding GH28 proteins, no growth was detected on citrus pectin as the sole carbon source. This indicates that the presence of only pectin-degrading lyases (PL1, PL3, PL4) in the genome of $M$. cinnamomea is not sufficient for the deconstruction of this polymer. The Ascomycete Podospora anserina also completely lacks family GH28 proteins and has similarly been found to grow very poorly on pectin substrates [61]. Surprisingly, only poor growth of $M$. cinnamomea FCH 10.5 was observed on cellulose (Avicel, CMC), despite the presence of a large number of genes encoding putative cellulose-degrading enzymes in its genome.

The induction of many CAZy genes upon transfer to cellulose- or hemicellulose-containing media happens within a few hours in A. fumigatus [62]. In M. cinnamomea $\mathrm{FCH} 10.5$, the transcriptional response to growth on xylan and wheat bran after 4 and $48 \mathrm{~h}$ of cultivation was clearly distinct from that on glucose; about $18 \%$ of all GH genes in the genome were being upregulated more than twofold. Most CAZy domain-containing genes with significantly increased expression when grown on wheat bran or xylan were predicted to target cellulose and hemicelluloses (xylan, xyloglucan, galacto(gluco) mannan) (Fig. 4). In particular, putative GH10 and GH11 endo- $\beta 1,4$-xylanases, GH43 $\beta 1,4$-xylosidases, CE5 acetyl xylan esterases and cutinases, a CE15 4-O-methyl-glucuronoyl methylesterase and a CE1 feruloyl esterase, as well as AA9 LPMOs, were more abundant on either xylan and wheat bran, or both. The bran fraction of wheat consists of about $16 \%$ proteins and $80 \%$ carbohydrates, the rest being mostly cutin, lignin, uronic acids, polyphenols, ferulic acid, phytic acid and minerals [63]. The starch content of wheat bran is about $10 \%$, and of the non-starch polysaccharides, arabinoxylans are the most prevalent (70\%), followed by cellulose (24\%) and $\beta$-glucan (6\%) [64]. The more complex composition of wheat bran was reflected in the upregulation of a more diverse set of CAZymes in M. cinnamomea than during growth on beechwood xylan, which is a comparatively simple substrate. Several genes that are not directly involved in the decomposition of xylan, such as AA9 LPMOs, which usually act on cellulose and xyloglucan, were nevertheless upregulated during growth on beechwood xylan. This shows that both xylan as well as more complex biomass (like wheat bran) can individually induce the expression of gene families generally known to be involved in cellulose and hemicellulose turnover. The expression of hemicellulose-degrading, but not cellulose-degrading, genes has been observed in Fusarium graminearum and
$N$. crassa when grown on xylan [65-67], while the concomitant induction of the cellulolytic system by XlnR has been reported for other fungi [62]. The poor growth of M. cinnamomea FCH 10.5 on cellulose (Avicel or CMC) was surprising (Fig. 1c), since its genome encodes many putative cellulolytic enzymes, including putative AA9 LPMOs. It needs to be investigated further if these AA9 proteins truly act on cellulose, or if they have activity on other polymers.

Wheat bran contains a considerable fraction of the waxy polymer cutin [68], and consequently we found several CE5 putative cutinases to be upregulated in $M$. cinnamomea when grown on wheat bran, one of which (MalCi_664.5) has recently been cloned and characterised [25]. Genes encoding CAZymes not involved in plant cell wall degradation were also found among the differentially expressed genes, e.g. two GH18 putative chitinases genes, and two genes with AA7 domains (gluco- or chitooligosaccharide oxidases), possibly involved in the reorganisation of the fungal cell wall.

Of the CBMs targeting different polymers, cellulosebinding CBM1s are particularly abundant in Ascomycetes and white-rot Basidiomycetes, with on average over $30 \%$ of CBMs belonging to family 1 [52]. The CBM1 abundance was unusually low in $M$. cinnamomea; only one member was found in a gene encoding a GH10CBM1 multimodular protein (MalCi_588.8). CBMs typically increase enzyme-substrate interaction, but low water content of the substrate has been shown to lead to equal hydrolytic performance of a cellulase with and without a CBM1, by enhancing the enzyme-substrate interaction irrespectively of the presence of a CBM1 $[51,69]$. The low number of CBMs, particularly CBM1s, in the genome of $M$. cinnamomea might, therefore, be a consequence of its occurrence in rather dry environments, such as compost, hay stacks and soil. We also discovered genes containing CBM domain(s), but lacking catalytic domain(s), which may point to yet unclassified functions and potentially new CAZy families. Eight genes with those structures were identified in the genome of FCH 10.5 (Fig. 3). For gene Malci_300.14, dbCAN predicted a single cellulose-binding CBM46 domain (CBM $\mathrm{X} 2$ in CDD search), which is a family found in GHs and scaffolding proteins of cellulosomes, and for which binding to bacterial cell walls and cellulose has been demonstrated [70]. Genes MalCi_332.1, MalCi_557.32 and MalCi_799.34 contain one or several CBM50 (CDD: LysM) domains and MalCi_326.2 a CBM18 domain, both of which can be part of chitinases and enzymes involved in bacterial cell wall degradation [71, 72]. A CBM48 domain was found in gene MalCi_589.58, which often has a glycogen-binding function, but can also be associated with starch-degrading enzymes, such as pullulanases or 
isoamylases [73]. A truncated predicted cellulose-binding CBM10 domain was identified in gene MalCi_664.9, a predicted starch-binding CBM21 domain in gene MalCi_808.4 and a predicted cellulose- or glucomannanbinding CBM16 domain in gene MalCi_427.10. Further studies are needed to determine the functions of these proteins.

A recent proteomic analysis of an $M$. cinnamomea strain cultivated on sorghum straw found a similar repertoire of secreted CAZymes to those inferred in the present study from the expression of CAZy domain-containing genes with predicted secretion signals (Table 2, Additional file 10), including many enzymes involved in the degradation of cellulose, hemicelluloses and chitin, as well as proteases and oxidases [26]. Interestingly, no AA9 family protein was identified in the secretome, although we found seven putative LPMOs with AA9 domains in the genome, four of which were upregulated on wheat bran and/or xylan, and one of which was among the 30 most highly expressed secreted CAZymes during growth on wheat bran. However, an AA8 family protein was found in the secretome [26], which can serve as an electron donor in the reduction of $\mathrm{Cu}$ (II) to $\mathrm{Cu}(\mathrm{I})$ in LPMOs [74]. We confirmed the presence of a single AA8 domaincontaining gene (MalCi_654.4) in the M. cinnamomea genome, transcribed during cultivation on all substrates, though not significantly differentially expressed. A gene containing a GH10 and a CBM1 domain was the only candidate we identified with a CBM1 domain, whereas Mahajan et al. found three: a GH10-CBM1, a CE15CBM1 and a GH6-CBM1 [26]. Neither the CE15 nor the GH6 domain was found to be associated with a CBM domain in the present study. All of the four GH10 genes identified in the genome of $M$. cinnamomea in this study (MalCi_210.5, MalCi_551.2, MalCi_551.3, MalCi_588.8) were expressed during growth on xylan, as well as during growth on wheat bran albeit to a much lower level (Additional file 10). Wheat bran is more similar in composition to the sorghum straw used by Mahajan et al. which may explain the detection of only three GH10 proteins in the secretome [26].

\section{Conclusions}

The findings of this study showcase the large repertoire of genes encoding CAZy domain-containing proteins in the genome of $M$. cinnamomea $\mathrm{FCH} 10.5$, a fungus which grows at high temperatures $\left(>50{ }^{\circ} \mathrm{C}\right)$ and is an efficient producer of many plant cell wall degrading enzymes. Genome sequencing and transcriptomics enabled the identification of genes actively involved in the degradation of xylan and wheat bran. The presented data enhance our understanding of fungal biodiversity, with special regard to differences in the mechanisms of plant cell wall degradation, and will facilitate the use of thermophilic enzymes produced by M. cinnamomea in biorefinery applications.

\section{Additional files}

Additional file 1. Comparison of characterised enzymes from M. cinnamomea from the literature, and their corresponding gene model from M. cinnamomea $\mathrm{FCH} 10.5$.

Additional file 2. Scatter plots of the biological replicates of the RNAseq data.

Additional file 3. Multiple and pairwise sequence alignments of $M$. cinnamomea ITS1-ITS2-5.8S-rRNA sequences deposited at Genbank.

Additional file 4. Xylanase and endoglucanase (CMCase) activities. Additional file 5. Growth of M. cinnamomea FCH 10.5 and four other filamentous fungi on mono- and polysaccharides.

Additional file 6. Genome statistics, BUSCO analysis output and BLAST hits of $M$. cinnamomea FCH 10.5 genome assembly.

Additional file 7. GO classification of annotated proteins in M. cinnamomea $\mathrm{FCH} 10.5$.

Additional file 8. Comparative analysis of the number of CAZy families (GHs, GTs, CEs, PLs, AAs, CBMs) in 24 different fungi.

Additional file 9. Phylogenetic tree of ITS1-ITS2-5.8S rRNA sequences.

Additional file 10. Average fpkm values of CAZy-domain containing transcripts expressed during growth on beechwood xylan, wheat bran and glucose.

Additional file 11. Differentially expressed genes of M. cinnamomea FCH 10.5 cultivated on wheat bran, beechwood xylan or glucose.

Additional file 12. GO enrichment of upregulated genes during cultivation on wheat bran or beechwood xylan, compared to glucose.

\section{Authors' contributions}

SH and TTN performed most of the experiments. SH, ZG, TCAW and DA performed the data analysis. SH designed the experiments and wrote the manuscript. JL, VNT and LO supervised the experiments and contributed to the writing and revision of the manuscript. All authors read and approved the final manuscript.

\section{Author details}

${ }^{1}$ Department of Biology and Biological Engineering, Division of Industrial Biotechnology, Chalmers University of Technology, 41296 Gothenburg, Sweden. ${ }^{2}$ Wallenberg Wood Science Center, Chalmers University of Technology, 41296 Gothenburg, Sweden. ${ }^{3}$ Centre for Industrial Microbiology, Food Industries Research Institute, Thanh Xuan, Ha Noi, Vietnam. ${ }^{4}$ GenomeScan B.V., Plesmanlaan 1/D, 2333 BZ Leiden, The Netherlands. ${ }^{5}$ National Bioinformatics Infrastructure Sweden (NBIS), Institute of Biology, Lund University, 223 62 Lund, Sweden.

\section{Acknowledgements}

This research was financially supported by the European Union OPTIBIOCAT project (FP7 KBBE. 2013.3.3-04; Grant Agreement No. 613868), by the Swedish Research Council (Vetenskapsrådet) Grant No. 2014-3523, and by the Wallenberg Wood Science Center, granted by the Wallenberg Foundation.

\section{Competing interests}

The authors declare that they have no competing interests.

\section{Availability of data and materials}

The datasets supporting the findings of this study are included within the article and as Additional files 1, 2, 3, 4, 5, 6, 7, 8, 9, 10, 11, 12. The genome assembly has been deposited at DDBJ/EMBL/GenBank under the assembly Accession No. FQSS00000000. The version described in this paper is the 
second version, FQS502000000. Transcriptome data are available in the ArrayExpress database [75] under Accession Number E-MTAB-6157.

\section{Publisher's Note}

Springer Nature remains neutral with regard to jurisdictional claims in published maps and institutional affiliations.

Received: 6 July 2017 Accepted: 4 November 2017

Published online: 13 November 2017

\section{References}

1. Cherubini F. The biorefinery concept: using biomass instead of oil for producing energy and chemicals. Energy Convers Manag. 2010;51:1412-21.

2. Kawaguchi $\mathrm{H}$, Hasunuma T, Ogino C, Kondo A. Bioprocessing of biobased chemicals produced from lignocellulosic feedstocks. Curr Opin Biotechnol. 2016:42:30-9.

3. Phitsuwan P, Sakka K, Ratanakhanokchai K. Improvement of lignocellulosic biomass in planta: a review of feedstocks, biomass recalcitrance, and strategic manipulation of ideal plants designed for ethanol production and processability. Biomass Bioenerg. 2013;58:390-405.

4. Guerriero G, Hausman J-F, Strauss J, Ertan H, Siddiqui KS. Lignocellulosic biomass: biosynthesis, degradation, and industrial utilization. Eng Life Sci. 2016:16:1-16

5. Cantarel BL, Coutinho PM, Rancurel C, Bernard T, Lombard V, Henrissat B. the carbohydrate-active enzymes database (CAZy): an expert resource for glycogenomics. Nucleic Acids Res. 2009;37:D233-8.

6. Levasseur A, Drula E, Lombard V, Coutinho PM, Henrissat B. Expansion of the enzymatic repertoire of the CAZy database to integrate auxiliary redox enzymes. Biotechnol Biofuels. 2013:6:41.

7. The carbohydrate-active enzymes database. http://www.cazy.org Accessed 06 Oct 2016.

8. Singh AP, Singh T. Biotechnological applications of wood-rotting fungi: a review. Biomass Bioenerg. 2014;62:198-206.

9. Liu G, Qin Y, Li Z, Qu Y. Development of highly efficient, low-cost lignocellulolytic enzyme systems in the post-genomic era. Biotechnol Adv. 2013:31:962-75

10. Zhao Z, Liu H, Wang C, Xu JJR. Comparative analysis of fungal genomes reveals different plant cell wall degrading capacity in fungi. BMC Genomics. 2013;14:274.

11. Bhalla A, Bansal N, Kumar S, Bischoff KM, Sani RK. Improved lignocellulose conversion to biofuels with thermophilic bacteria and thermostable enzymes. Bioresour Technol. 2013:128:751-9.

12. Kumar V, Marín-Navarro J, Shukla P. Thermostable microbial xylanases for pulp and paper industries: trends, applications and further perspectives. World J Microbiol Biotechnol. 2016:32:1-10.

13. Szijártó N, Horan E, Zhang J, Puranen T, Siika-Aho M, Viikari L. Thermostable endoglucanases in the liquefaction of hydrothermally pretreated wheat straw. Biotechnol Biofuels. 2011;4:2

14. Viikari L, Alapuranen M, Puranen T, Vehmaanperä J, Siika-Aho M. Thermostable enzymes in lignocellulose hydrolysis. Adv Biochem Eng Biotechnol. 2007:108:121-45.

15. Taylor TJ, Vaisman II. Discrimination of thermophilic and mesophilic proteins. BMC Struct Biol. 2010;10(Suppl 1):S5.

16. Busk PK, Lange L. Cellulolytic potential of thermophilic species from four fungal orders. AMB Express. 2013;3:47.

17. Morgenstern I, Powlowski J, Ishmael N, Darmond C, Marqueteau S, Moisan MC, et al. A molecular phylogeny of thermophilic fungi. Fungal Biol. 2012;116:489-502.

18. Ahirwar S, Soni H, Rawat HK, Ganaie MA, Pranaw K, Kango N. Production optimization and functional characterization of thermostable $\beta$-mannanase from Malbranchea cinnamomea NFCCI 3724 and its applicability in mannotetraose (M4) generation. J Taiwan Inst Chem Eng. 2016;63:1-10

19. Yang $S$, Xiong $H$, Yan $Q$, Yang $H$, Jiang $Z$. Purification and characterization of a novel alkaline $\beta-1,3-1,4-$ glucanase (lichenase) from thermophilic fungus Malbranchea cinnamomea. J Ind Microbiol Biotechnol. 2014:41:1487-95.
20. Han P, Zhou P, Hu S, Yang S, Yan Q, Jiang Z. A novel multifunctional a-amylase from the thermophilic fungus Malbranchea cinnamomea: biochemical characterization and three-dimensional structure. Appl Biochem Biotechnol. 2013;170:420-35.

21. Yan QJ, Han P, Yang SQ, Jiang ZQ. Purification and characterization of a novel a-glucosidase from Malbranchea cinnamomea. Biotechnol Lett. 2015:37:1279-86.

22. Fan G, Yang S, Yan Q, Guo Y, Li Y, Jiang Z. Characterization of a highly thermostable glycoside hydrolase family 10 xylanase from Malbranchea cinnamomea. Int J Biol Macromol. 2014;70:482-9.

23. Matsuo M, Yasui T. Properties of Xylanase of Malbranchea pulchella var. sulfurea N. 48. Agric Biol Chem. 1985;49:839-41.

24. Ribeiro LF, De Lucas RC, Vitcosque GL, Ribeiro LF, Ward RJ, Rubio MV et al. A novel thermostable xylanase $\mathrm{GH} 10$ from Malbranchea pulchella expressed in Aspergillus nidulans with potential applications in biotechnology. Biotechnol Biofuels. 2014;7:115.

25. Duan X, Liu Y, You X, Jiang Z, Yang S, Yang S. High-level expression and characterization of a novel cutinase from Malbranchea cinnamomea suitable for butyl butyrate production. Biotechnol Biofuels. 2017;10:223.

26. Mahajan C, Basotra N, Singh S, Di Falco M, Tsang A, Chadha BS. Malbranchea cinnamomea: a thermophilic fungal source of catalytically efficient lignocellulolytic glycosyl hydrolases and metal dependent enzymes. Bioresour Technol. 2016;200:55-63.

27. Publicly released genomes sequenced and annotated by the Genozymes project. http://www.fungalgenomics.ca/wiki/Fungal_Genomes. Accessed 30 June 2016.

28. Esteve-Zarzoso B, Belloch C, Uruburu F, Querol A. Identification of yeasts by RFLP analysis of the 5.8S rRNA gene and the two ribosomal internal transcribed spacers. Int J Syst Bacteriol. 1999:49:329-37.

29. Westerdijk fungal biodiversity institute. http://www.westerdijkinstitute.nl. Accessed 31 Aug 2017

30. Sambrook J, Russell DW. Purification of nucleic acids by extraction with phenol: chloroform. Cold Spring Harb Protoc. 2006. https://doi. org/10.1101/pdb.prot4455.

31. Anders S, Huber W, Nagalakshmi U, Wang Z, Waern K, Shou C, et al. Differential expression analysis for sequence count data. Genome Biol. 2010;11:R106.

32. Simpson JT, Wong K, Jackman SD, Simpson JT, Wong K, Jackman SD, et al. ABySS: a parallel assembler for short read sequence data. Genome Res. 2009:19:1117-23.

33. Majoros WH, Pertea M, Salzberg SL. TigrScan and GlimmerHMM: two open source ab initio eukaryotic gene-finders. Bioinformatics. 2004;20:2878-9.

34. The genome of Uncinocarpus reesii. http://genome.jgi.doe.gov/Uncre1/ Uncre1.home.html. Accessed 08 Jan 2017.

35. Testa AC, Hane JK, Ellwood SR, Oliver RP. CodingQuarry: highly accurate hidden Markov model gene prediction in fungal genomes using RNAseq transcripts. BMC Genomics. 2015;16:170.

36. BLAST_Basic local alignment search tool. https://blast.ncbi.nlm.nih.gov. Accessed 05 Mar 2016.

37. Conesa A, Götz S. Blast2GO: a comprehensive suite for functional analysis in plant genomics. Int J Plant Genomics. 2008. https://doi. org/10.1155/2008/619832.

38. Väremo L, Nielsen J, Nookaew I. Enriching the gene set analysis of genome-wide data by incorporating directionality of gene expression and combining statistical hypotheses and methods. Nucleic Acids Res. 2013:41:4378-91.

39. Petersen TN, Brunak S, von Heijne G, Nielsen H. SignalP 4.0: discriminating signal peptides from transmembrane regions. Nat Methods. 2011:8:785-6.

40. Horton P, Park KJ, Obayashi T, Fujita N, Harada H, Adams-Collier CJ, et al. WoLF PSORT: protein localization predictor. Nucleic Acids Res. 2007;35:585-7

41. Yin Y, Mao X, Yang J, Chen X, Mao F, Xu Y. dbCAN : a web resource for automated carbohydrate-active enzyme annotation. Nucleic Acids Res. 2012:40:445-51.

42. Marchler-Bauer A, Derbyshire MK, Gonzales NR, Lu S, Chitsaz F, Geer LY, et al. CDD: NCBI's conserved domain database. Nucleic Acids Res. 2015:43:D222-6.

43. Sigler L. Trichothecium cinnamomeum, an earlier name for the thermophilic hyphomycete Malbranchea sulfurea. Mycol; 1987. 
44. Mahajan C, Chadha BS, Nain L, Kaur A. Evaluation of glycosyl hydrolases from thermophilic fungi for their potential in bioconversion of alkali and biologically treated Parthenium hysterophorus weed and rice straw into ethanol. Bioresour Technol. 2014;163:300-7.

45. Gregory TR, Nicol JA, Tamm H, Kullman B, Kullman K, Leitch IJ, et al. Eukaryotic genome size databases. Nucleic Acids Res. 2007;35:332-8.

46. Genome sizes and number of genes of Eurotiomycetes available at JGI MycoCosm. http://genome.jgi.doe.gov/eurotiomycetes/eurotiomycetes. info.html. Accessed 10 Sept 2017.

47. Simão FA, Waterhouse RM, loannidis P, Kriventseva EV, Zdobnov EM. BUSCO: assessing genome assembly and annotation completeness with single-copy orthologs. Bioinformatics. 2015;31:3210-2.

48. Battaglia E, Benoit I, van den Brink J, Wiebenga A, Coutinho PM, Henrissat $B$, et al. Carbohydrate-active enzymes from the zygomycete fungus Rhizopus oryzae: a highly specialized approach to carbohydrate degradation depicted at genome level. BMC Genomics. 2011;12:38.

49. Couturier M, Bennati-Granier C, Urio MB, Ramos LP, Berrin J-G. Fungal enzymatic degradation of cellulose. In: Soccol C, Brar S, Faulds C, Ramos L, editors. Green Fuels Technol. Springer: Cham; 2016. p. 133-46.

50. Martens-Uzunova ES, Schaap PJ. Assessment of the pectin degrading enzyme network of Aspergillus niger by functional genomics. Fungal Genet Biol. 2009;46(Suppl 1):S170-9.

51. Várnai A, Siika-Aho M, Viikari L. Carbohydrate-binding modules (CBMs) revisited: reduced amount of water counterbalances the need for CBMs. Biotechnol Biofuels. 2013;6:30

52. Várnai A, Mäkelä MR, Djajadi DT, Rahikainen J, Hatakka A, Viikari L. Carbohydrate-binding modules of fungal cellulases. Occurrence in nature, function, and relevance in industrial biomass conversion. Adv Appl Microbiol. 2014;88:103-65.

53. Ao J, Free SJ. Genetic and biochemical characterization of the GH72 family of cell wall transglycosylases in Neurospora crassa. Fungal Genet Biol. 2017;101:46-54.

54. Gruber S, Vaaje-Kolstad G, Matarese F, López-Mondéjar R, Kubicek CP, Seidl-Seiboth $V$. Analysis of subgroup $C$ of fungal chitinases containing chitin-binding and LysM modules in the mycoparasite Trichoderma atroviride. Glycobiology. 2011;21:122-33.

55. Kroon PA, Garcia-Conesa MT, Fillingham IJ, Hazlewood GP, Williams G. Release of ferulic acid dehydrodimers from plant cell walls by feruloyl esterases. J Sci Food Agric. 1999;434:428-34.

56. Arnling Bååth J, Giummarella N, Klaubauf S, Lawoko M, Olsson L. A glucuronoyl esterase from Acremonium alcalophilum cleaves native lignincarbohydrate ester bonds. FEBS Lett. 2016;590:2611-8.

57. Kunitake E, Kobayashi T. Conservation and diversity of the regulators of cellulolytic enzyme genes in Ascomycete fungi. Curr Genet. 2017:63:951-8.

58. Singh B, Poças-Fonseca MJ, Johri BN, Satyanarayana T. Thermophilic molds: biology and applications. Crit Rev Microbiol. 2016;7828:1-22.

59. Benoit I, Culleton H, Zhou M, DiFalco M, Aguilar-Osorio G, Battaglia E, et al. Closely related fungi employ diverse enzymatic strategies to degrade plant biomass. Biotechnol Biofuels. 2015. https://doi.org/10.1186/ s13068-015-0285-0.

60. Maheshwari R, Bharadwaj G, Bhat MK. Thermophilic fungi: their physiology and enzymes. Microbiol Mol Biol Rev. 2000;64:461-88.

61. Espagne E, Lespinet O, Malagnac F, Da Silva C, Jaillon O, Porcel BM, et al. The genome sequence of the model ascomycete fungus Podospora anserina. Genome Biol. 2008;9:77.

62. Miao Y, Liu D, Li G, Li P, Xu Y, Shen Q, et al. Genome-wide transcriptomic analysis of a superior biomass-degrading strain of $A$. fumigatus revealed active lignocellulose-degrading genesBMC. Genomics. 2015;16:459.

63. Stevenson L, Phillips F, O'Sullivan K, Walton J. Wheat bran: its composition and benefits to health, a European perspective. Int J Food Sci Nutr. 2012;63:1001-13.

64. Prückler M, Siebenhandl-Ehn S, Apprich S, Höltinger S, Haas C, Schmid E, et al. Wheat bran-based biorefinery 1: composition of wheat bran and strategies of functionalization. LWT Food Sci. Technol. 2014;56:211-21.

65. Brunner K, Lichtenauer AM, Kratochwill K, Delic M, Mach RL. Xyr1 regulates xylanase but not cellulase formation in the head blight fungus Fusarium graminearum. Curr Genet. 2007;52:213-20.

66. Klaubauf S, Narang HM, Post H, Zhou M, Brunner K, Mach-Aigner AR et al. Similar is not the same: differences in the function of the (hemi-) cellulolytic regulator XInR (XIr1/Xyr1) in filamentous fungi. Fungal Genet Biol. 2014;72:73-81.
67. Sun J, Tian C, Diamond S, Louise Glassa N. Deciphering transcriptional regulatory mechanisms associated with hemicellulose degradation in Neurospora crassa. Eukaryot Cell. 2012;11:482-93.

68. Ha M, Jardine WG, Jarvis MC. 13 C NMR of Cell Walls in Wheat Bran. J Agric Food Chem. 1997:45:117-9.

69. Le Costaouëc T, Pakarinen A, Várnai A, Puranen T, Viikari L. The role of carbohydrate binding module (CBM) at high substrate consistency: comparison of Trichoderma reesei and Thermoascus aurantiacus Cel7A (CBHI) and Cel5A (EGII). Bioresour Technol. 2013;143:196-203.

70. Liu G, Qin Y, Hu Y, Gao M, Peng S, Qu Y. An endo-1,4- $\beta$-glucanase PdCel5C from cellulolytic fungus Penicillium decumbens with distinctive domain composition and hydrolysis product profile. Enzyme Microb Technol. 2013;52:190-5

71. Dubovskii PV, Vassilevski AA, Slavokhotova AA, Odintsova TI, Grishin EV, Egorov TA, et al. Solution structure of a defense peptide from wheat with a 10-cysteine motif. Biochem Biophys Res Commun. 2011;411:14-8.

72. Buist G, Steen A, Kok J, Kuipers OP. LysM, a widely distributed protein motif for binding to (peptido)glycans. Mol Microbiol. 2008;68:838-47.

73. Peng C, Wang Y, Liu F, Ren Y, Zhou K, Lv J, et al. FLOURY ENDOSPERM6 encodes a CBM48 domain-containing protein involved in compound granule formation and starch synthesis in rice endosperm. Plant J. 2014:77:917-30.

74. Phillips CM, Beeson WT, Cate JH, Marletta MA. Cellobiose dehydrogenase and a copper-dependent polysaccharide monooxygenase potentiate cellulose degradation by Neurospora crassa. ACS Chem Biol. 2011;6:1399-406

75. ArrayExpress - Archive of functional genomics data. http://www.ebi. ac.uk/arrayexpress. Accessed 05 Sept 2017.

76. Ohm RA, de Jong JF, Lugones LG, Aerts A, Kothe E, Stajich JE, et al. Genome sequence of the model mushroom Schizophyllum commune. Nat Biotechnol. 2010;28:957-63.

77. Genome sequence of the white rot fungus Schizophyllum commune. http://genome.jgi.doe.gov/Schco3/Schco3.home.html. Accessed 08 Oct 2016.

78. Martinez D, Larrondo LF, Putnam N, Gelpke MDS, Huang K, Chapman J, et al. Genome sequence of the lignocellulose degrading fungus Phanerochaete chrysosporium strain RP78. Nat Biotechnol. 2004;22:695-700.

79. Genome sequence of the white rot fungus Phanerochaete chrysosporium. http://genome.jgi.doe.gov/Phchr2/Phchr2.home.html. Accessed 10 Oct 2016.

80. Martinez D, Challacombe J, Morgenstern I, Hibbett D, Schmoll M, Kubicek CP, et al. Genome, transcriptome, and secretome analysis of wood decay fungus Postia placenta supports unique mechanisms of lignocellulose conversion. Proc Natl Acad Sci USA. 2009;106:1954-9.

81. The genome sequence of the brown rot fungus Postia placenta. http:// genome.jgi.doe.gov/Pospl1/Pospl1.home.html. Accessed 12 Oct 2016.

82. Genome sequence of Rhizopus oryzae. http://genome.jgi.doe.gov/Rhior3/ Rhior3.home.html. Accessed 10 Oct 2016.

\section{Submit your next manuscript to BioMed Central and we will help you at every step:}

- We accept pre-submission inquiries

- Our selector tool helps you to find the most relevant journal

- We provide round the clock customer support

- Convenient online submission

- Thorough peer review

- Inclusion in PubMed and all major indexing services

- Maximum visibility for your research

Submit your manuscript at www.biomedcentral.com/submit 